Provided for non-commercial research and education use. Not for reproduction, distribution or commercial use.

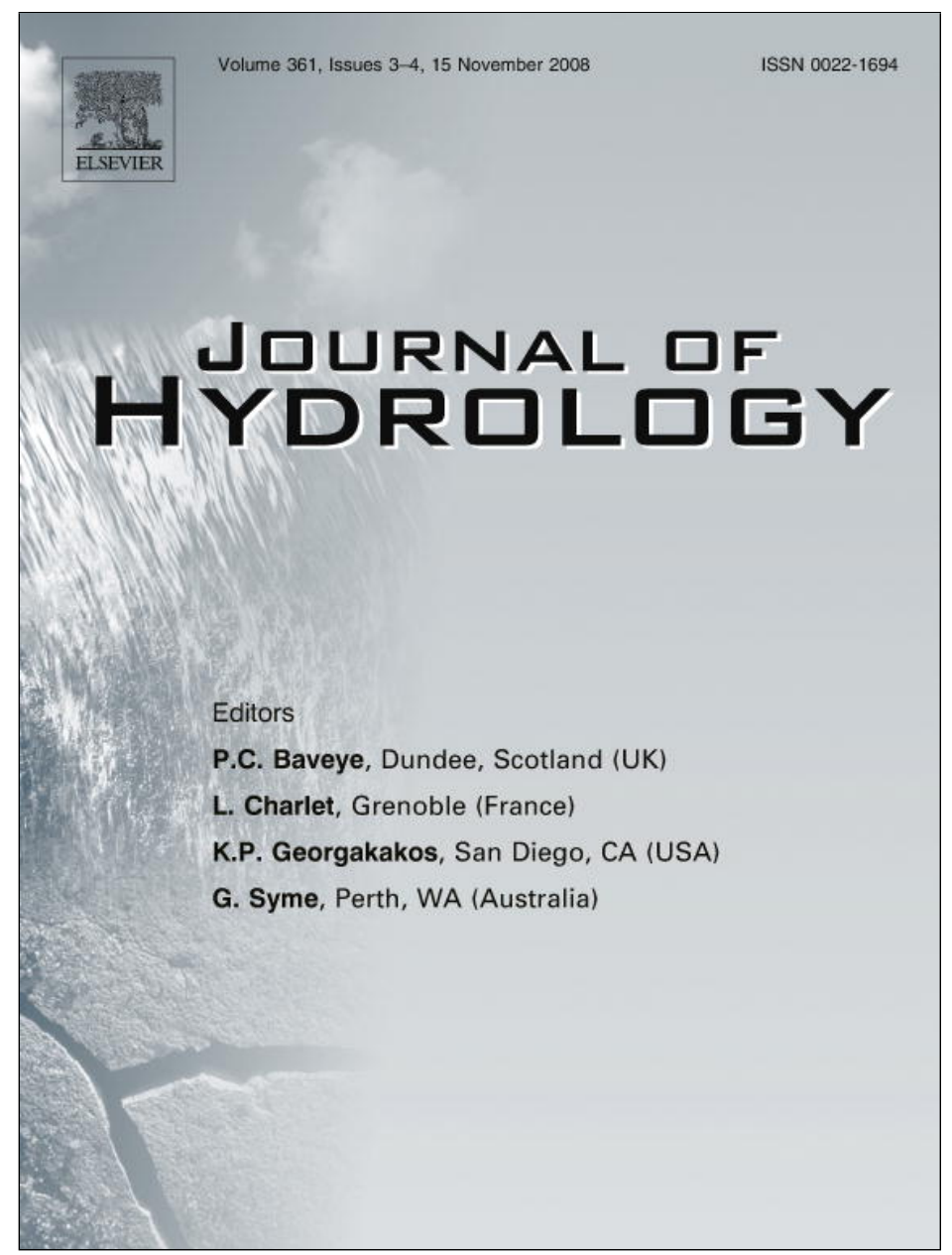

This article appeared in a journal published by Elsevier. The attached copy is furnished to the author for internal non-commercial research and education use, including for instruction at the authors institution and sharing with colleagues.

Other uses, including reproduction and distribution, or selling or licensing copies, or posting to personal, institutional or third party websites are prohibited.

In most cases authors are permitted to post their version of the article (e.g. in Word or Tex form) to their personal website or institutional repository. Authors requiring further information regarding Elsevier's archiving and manuscript policies are encouraged to visit:

http://www.elsevier.com/copyright 


\title{
The use of one- and two-dimensional hydraulic modelling to reconstruct a glacial outburst flood in a steep Alpine valley
}

\author{
P. Bohorquez ${ }^{a, *}$, S.E. Darby ${ }^{b}$ \\ a ETS Ingenieros Industriales, Universidad de Málaga, 29013 Málaga, Spain \\ b School of Geography, University of Southampton, Highfield, Southampton SO17 1BJ, UK
}

Received 16 January 2008; received in revised form 17 July 2008; accepted 28 July 2008

KEYWORDS

Palaeoflood;

Outburst;

Uncertainty;

Modelling

\begin{abstract}
Summary The hydrologic characteristics of the 1943 outburst flood from the Glacier du Mont Miné, Switzerland, are herein reconstructed using field evidence (palaeostage indicators) in conjunction with shallow water modelling techniques. These techniques rely on accurately characterising the hydraulic roughness of the channel, the water height established as boundary conditions, and the main flow path during the former flood, but the selection of appropriate parameter values can be problematic and hence there is uncertainty in the estimated discharge. In this study, minimal flow discharge estimates derived from one-dimensional modelling were found to vary between 429 and $557 \mathrm{~m}^{3} \mathrm{~s}^{-1}$ as the hydraulic roughness $\left(k_{\mathrm{s}}\right)$ and water height at the inlet were varied over a realistic range of values $(0.8-1.4 \mathrm{~m}$ and $3.31-6 \mathrm{~m}$, respectively), whereas flow rates derived via twodimensional modelling were confined in a narrower, lower, range of $358-454 \mathrm{~m}^{3} \mathrm{~s}^{-1}$. This degree of sensitivity to bed roughness $k_{\mathrm{s}}$, boundary conditions and the spatial dimensions of the modelling approach is, for the one-dimensional modelling, higher than reported in previous studies, but the precision of flow discharge values reconstructed using the twodimensional modelling approach appears to be acceptable, even for floods in the very steep valley $(0.1 \mathrm{~m} / \mathrm{m})$ that is subject of this study.

(c) 2008 Elsevier B.V. All rights reserved.
\end{abstract}

\section{Introduction}

Rare, high-magnitude flood events are capable of producing spectacular river channel changes (Bretz, 1923; Baker,

\footnotetext{
* Corresponding author. Tel.: +34 952136565.

E-mail address: pbohorquez@uma.es (P. Bohorquez).
}

1977; Gupta, 1988). Despite their intrinsic interest, knowledge of catastrophic events remains scant because they are rarely monitored (Baker and Kale, 1998). This lack of data has important implications for applications in the field of flood hydrology (Enzel et al., 1996). Of particular significance is that the availability of flood data has important repercussions in estimating the probable maximum flood 
(PMF), which is sensitive to the incidence of large floods (Acreman, 1989). Reliable PMF estimates are important because these inform such aspects as flood-risk mapping (Arnell, 1992), as well as the selection of design flood magnitudes used in the calculation of safety factors for dams, bridges, and other engineering structures (Brown, 1996).

These practical issues are particularly acute in mountain regions because systematic hydrological records are sparse. Moreover, since high mountain regions are often glaciated, the potential exists for catastrophic flooding associated with the sudden drainage of glacier- or moraine-impounded lakes (Haeberli, 1983; Haeberli et al., 1989; Evans and Clague, 1994; Tweed and Russell, 1999). In recent years there has also been a shift towards greater residential and recreational use of mountain regions (Pruess et al., 1998). Not only are increased numbers of people therefore at risk, but the effects of floods in mountain regions are pronounced, because steep valleys amplify the energy exerted by flowing water and sediment. In addition to the flood itself, associated hazards include channel adjustment, mobilisation of debris flows, and activation of slope instability, the effects of which may extend for some time after the triggering event (Desloges and Church, 1992; Evans and Clague, 1994; Walder and Driedger, 1994; Clague and Evans, 1997). For all these reasons, methods of reconstructing the hydrologic and hydraulic characteristics of unrecorded highmagnitude events are a key means of supplementing the hydrological record and supporting objective analyses of the hazards posed by catastrophic events.

Two distinct, but mutually complementary, methodological approaches have been used to reconstruct the hydrologic and hydraulic characteristics of palaeofloods. First, some investigators have attempted to interpret the sediments deposited by former floods, using a variety of sedimentological indicators such as particle size, sorting, fabric and shape measures to infer palaeoflow parameters such as stream competence, flow direction, and flow velocity (Costa, 1983; Williams, 1983; Carling, 1996; Maizels, 1997). This approach relies on the use of equations derived from modern rivers in which a specific sedimentological characteristic (e.g. particle size) is linked to the palaeoflood parameter (e.g. flow velocity) via a relevant physical relationship, such as flow resistance (Williams, 1984). The second approach relies on the identification of palaeostage indicators (PSI) using geomorphic (Baker, 1973; Shroba et al., 1979; Wohl, 1995), sedimentary (Kochel and Baker, 1988; O'Connor et al., 1994); and/or botanical (Gregory, 1976; Hupp, 1988) evidence. If sufficient PSI are identified, hydraulic modelling can be undertaken to retrodict the peak flow discharge required to match the inferred elevation of the former flood. Palaeoflood reconstruction using onedimensional step-backwater modelling (Davidian, 1984) has become a popular palaeohydrologic tool and has been used to refine estimates of former floods in a variety of settings (Kochel et al., 1982; Baker, 1987; Baker et al., 1993; Carling and Grodek, 1994; Benito, 1997). More recently, a number of studies have started to employ the more sophisticated two-dimensional versions of the shallow water equations (e.g. Miller, 1998; Miller and Cluer, 1998; Eskilsson et al., 2002; Denlinger and O'Connell, 2003). Two-dimensional approaches are likely to be more appropriate for accurately simulating extreme outburst events, given their ability to characterise unsteady flows, dynamic waves, and supercritical flows (Carrivick, 2006; Carrivick, 2007), but few studies have systematically compared the potential and limitations of one- versus two-dimensional modelling in the context of palaeoflood reconstruction (e.g. Alho and Aaltonen, 2008).

The reliability of flood reconstruction techniques has been addressed in a number of reviews (Kochel and Baker, 1988; Komar, 1989; Williams, 1984; Cook, 1987) which show that the accuracy and precision of results are conditioned by the reliability of available evidence, and by the validity of assumptions involved in applying palaeoflood models. However, few studies have systematically evaluated the level of uncertainty involved in parameterizing the hydraulic modelling used to reconstruct former events (Wohl, 1998; Kidson et al., 2006). Whether using a one- or two-dimensional modelling approach, there is clear potential for uncertainty to be introduced into retrodicted estimates of palaeoflood magnitude due to the well known difficulties associated with parameterizing the roughness values and boundary conditions used in the modelling (e.g. Pappenberger et al., 2005; Wohl, 1998; Kidson et al., 2006). What is not clear is the extent to which such uncertainties vary as a function of the more traditional one-dimensional modelling approaches and emerging two-dimensional techniques.

In this study, a previously undocumented glacial outburst event in the Swiss Alps is used as a case study to identify some of the uncertainties associated with employing hydraulic modelling, in conjunction with PSI evidence, to reconstruct the peak flow discharge of such events. It is well known that glacial outburst events encompass a huge variation in magnitude (peak flow discharges ranging from $\sim 10^{0} \mathrm{~m}^{3} \mathrm{~s}^{-1}$, Beecroft, 1981 , to up to $\sim 10^{6} \mathrm{~m}^{3} \mathrm{~s}^{-1}$; Baker, 1973; Baker et al., 1993). Although the magnitude of the peak discharge of the event in this study falls at the lower end of this range $\left(Q_{\mathrm{p}} \approx 10^{2} \mathrm{~m}^{3} \mathrm{~s}^{-1}\right)$, well preserved evidence of the event, in the form of numerous PSI, exists within a bedrock gorge located very close to the glacier from which the flood originated. As such the study site is, on the face of it, ideal for the application of hydraulic modelling techniques that seek to fit simulated water surface profiles to field evidence of peak flood stage. The main aim of our study is to evaluate the extent to which uncertainties inherent in selecting values of roughness parameters and boundary conditions for use in the flow modelling, even with such well constrained field evidence, feed through to associated uncertainties in the estimation of the retrodicted flood discharge. A key novel aspect of our work is that the analysis is undertaken for two separate modelling approaches that employ one- and two-dimensional representations of the governing Navier-Stokes equations, respectively. In this way we are able to systematically evaluate the effects of both parameter and model structural uncertainties on retrodicted palaeoflood magnitudes.

\section{Field area}

This study is concerned with an outburst flood that occurred in August 1943 when an englacial lake broke through the side of the Glacier du Mont Miné in the Ferpècle Valley. This val- 
ley forms the eastern branch of the Val d'Hérens in the Valais region of Switzerland and represents a typical steep, highrelief, Alpine valley system, draining an area of some
$62.9 \mathrm{~km}^{2}$ above Les Haudéres (Fig. 1). Some $45 \%$ of the catchment is glaciated, and the topography ranges between 1535 and $3500 \mathrm{~m}$ in elevation (mean elevation $=2870 \mathrm{~m}$ ).
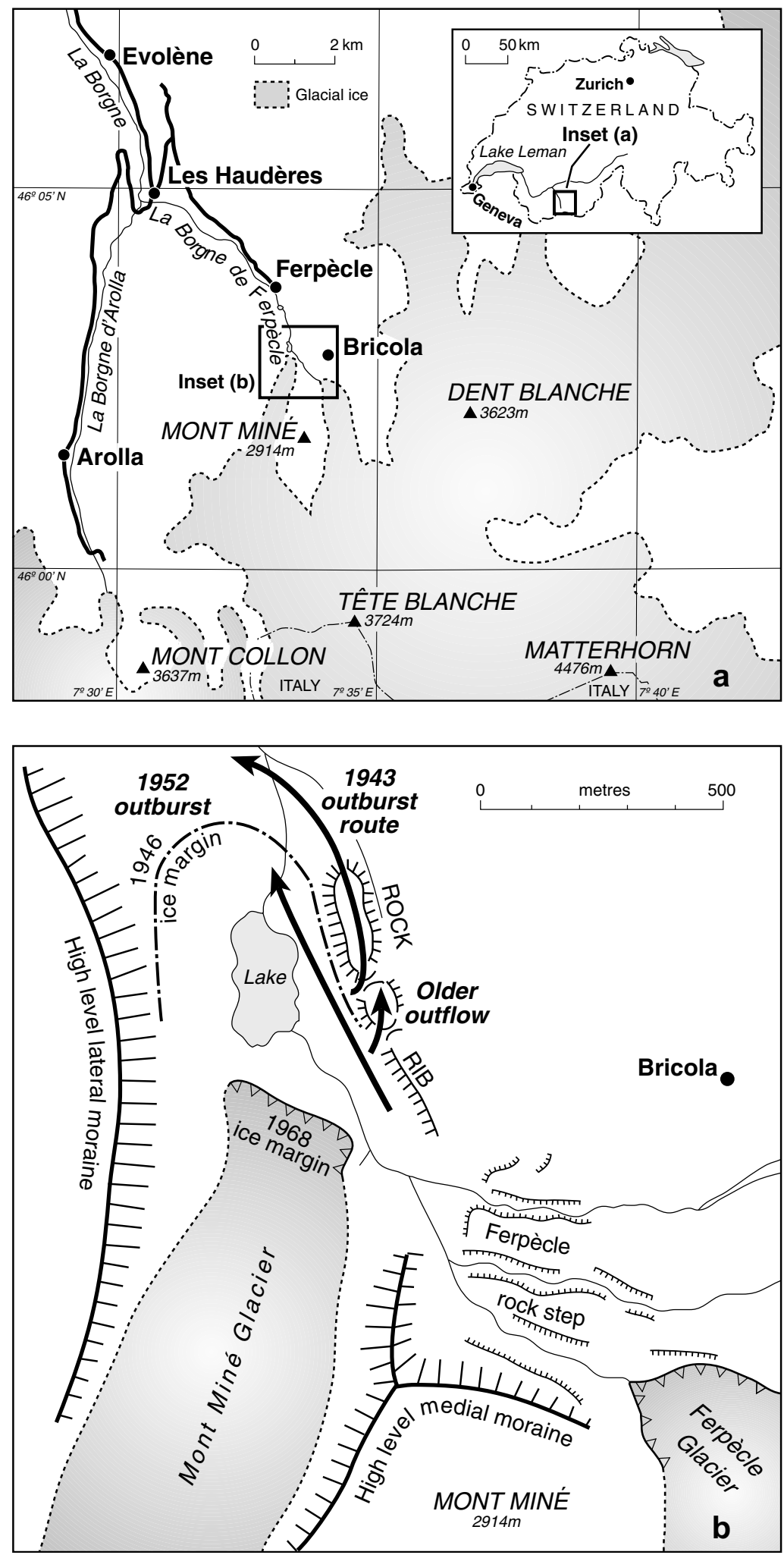

Figure 1 (a) Location of the study reach in the Val d'Hérens, Switzerland. The inset (b) in (a) depicts a detailed map showing the geomorphological context of the flood channel. 
Orographic effects produce a highly variable precipitation distribution, and lower reaches are much drier (600$800 \mathrm{~mm}$ of precipitation each year) than in the high mountains, where annual precipitation exceeds $3600 \mathrm{~mm}$, much of which falls as snow (Commune d'Evolène, 1998).

Under natural conditions, snow and glacial melt dominate runoff from the Ferpècle basin above Les Haudères, with 'normal' flood events occurring after intense convective storms in the summer months. Since 1965 the hydrological regime has been impacted by the Grande Dixence hydropower scheme. This scheme was constructed to capture meltwater from the major glaciers in the Zermatt valley and Val d'Hérens. Water is collected through a system of intake structures located on the main proglacial streams and transferred into a single conduit (the Haut Gallerie) that discharges into a large $\left(400 \mathrm{M} \mathrm{m}^{3}\right)$ storage reservoir in the Val des Dix to the west. Water transfers from the Borgne de Ferpècle have consequently all but eliminated flood flows below $8.4 \mathrm{~m}^{3} \mathrm{~s}^{-1}$. Nevertheless, the risk of flooding from high-magnitude flows remains, and efforts have been made to assess the probabilities of such events. The approaches used have been based on the limited hydrological data available at the Les Haudères gauge (1950-1956), and modelling based on measured extreme precipitation scenarios. Results from these two methods are in close agreement, with the 100- and 1000-year return period flows at Les Haudères estimated to be around 70 and $100 \mathrm{~m}^{3} \mathrm{~s}^{-1}$, respectively (Commune d'Evolène, 1998).

Unfortunately, flood-risk in the Ferpècle Valley is probably under-estimated because hazardous glacial outburst floods are unaccounted for. In Switzerland as a whole, such floods occur once every 1-2 years (Haeberli, 1983) and, within the Ferpècle Valley, outburst events are known to have occurred in 1943 and in 1952. Beyond these two documented events, the jökulhlaup history of the field area is unknown, though it is likely that such events have ocurred previously in the past. The latter event was generated by a water-pocket rupture from the Glacier de Ferpècle and had an estimated peak discharge of some $230 \mathrm{~m}^{3} \mathrm{~s}^{-1}$ at Les Haudères (Haeberli, 1983). The 1943 Mont Miné outburst has not previously been investigated and hence the magnitude of this event is not well defined. While one contemporary eyewitness account (Hagen, 1944) suggested that surface flow velocities exceeded $3 \mathrm{~m}^{3} \mathrm{~s}^{-1}$, only a crude estimate of the cross-section area of the flow could be made, and the resulting estimate of peak flow discharge $\left(90 \mathrm{~m}^{3} \mathrm{~s}^{-1}\right)$ must be regarded as highly speculative. However, similar to the 1952 outburst, the 1943 Mont Miné flood can certainly be regarded as exceptional in that it greatly exceeds the magnitude of the flood of record $\left(38 \mathrm{~m}^{3} \mathrm{~s}^{-1}\right.$ for gauging period 1950-1956) at Les Haudères, this latter flood being generated by exceptional rainfall. The catastrophic nature of the Mont Miné outburst is also evident from its geomorphic impact. The event carved a $0.5-\mathrm{km}$ long channel (Fig. 2) immediately downstream of the glacier, while further downstream large boulder splays were deposited, and every bridge crossing down to Sion in the Rhône valley, a distance of some $40 \mathrm{~km}$, was also destroyed (Hagen, 1944).

While PSI evidence of both outburst events is plentiful, it is not possible to isolate which event is associated with a given PSI in reaches downstream of the bedrock channel. However, the geomorphic context of the bedrock channel reach does allow an unequivocal interpretation that PSI preserved within this reach are associated only with the 1943 event. Specifically, the Glacier du Mont Miné and the Glacier de Ferpècle have since at least 1900 (when they were joined at their snouts) been rapidly retreating (ca. $25 \mathrm{~m} \mathrm{yr}^{-1}$ ) and downwasting. A series of well-preserved and dated moraines charts the detailed history of this period of retreat accurately. The inlet of the bedrock channel that forms the focus of this study is in contact with a kame terrace that indicates the position of the Glacier du Mont Miné ice margin in 1946. By 1952 the margin of the Glacier

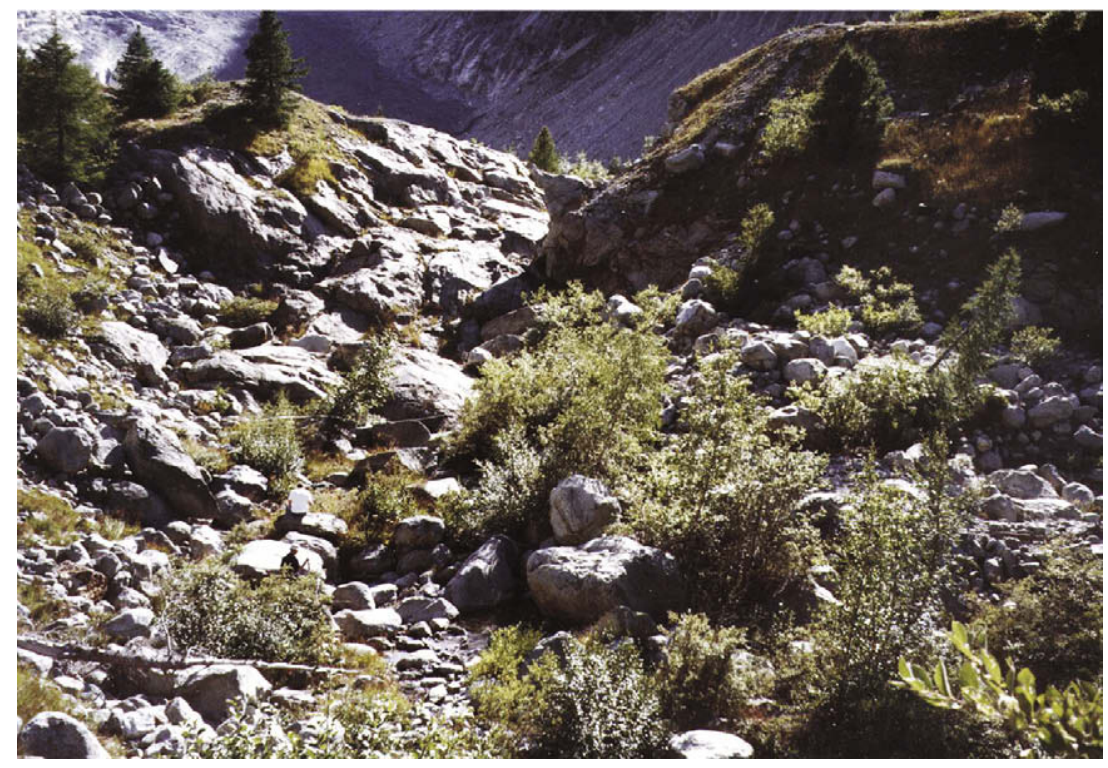

Figure 2 Photograph of the upper portion of the study reach. The view is south towards the inlet of the gorge, which in 1943 was in contact with the Glacier du Mont Miné. The person in the left foreground provides an indication of scale. 
de Ferpècle had retreated and down-wasted sufficiently that flood waters from this later outburst could not feasibly have risen to the elevation of the 1943 channel, and instead would have bypassed it at a lower elevation (Fig. 1). Consequently, the short bedrock channel reach represents the only evidence of the 1943 Mont Miné outburst that can unequivocally be attributed to that event alone.

\section{Palaeoflood reconstruction}

\section{Field data collection}

The topography of the study reach was determined by electronic distance measurer (EDM) survey during 5-12 September, 2000. Due to the rugged nature of the terrain (Fig. 2), it was difficult to undertake surveys along fixed cross-section transects. A high-resolution (3225 points) free survey of the reach was, therefore, undertaken with the surveyed coordinates used subsequently in Matlab to construct an elevation model of the reach (Fig. 3). There are a variety of numerical approaches for doing this. For proof of principle we utilise approximation (D'Errico, 2006) as opposed to interpolation so that it is robust to noise and outliers. This technique best fits the elevation model to the surveyed points, subject to a smoothness constraint, using a modified ridge estimator with a triangle interpolation scheme. The elevation model was built using $500 \times 500(x, y)$ points. The mean and maximum value of the bed slope of the study reach are 0.10 and $0.43 \mathrm{~m} / \mathrm{m}$, respectively, which is very steep. Since the one-dimensional hydraulic model used herein requires the channel topography to be characterised using a series of cross-sections spaced along the channel (see below), these were subsequently extracted from the elevation model by a 'slicing' procedure. This afforded the advantage that the positions and density of cross-sections could be varied after the survey to match the modelling requirements. In particular, a total of 360 crosssections (1 $\mathrm{m}$ spacing), uniformly distributed along the main flow path, were extracted to describe the one-dimensional topography. The main flow path was subdivided into six straight reaches that model the channel bends with curved joints between consecutive reaches, thereby avoiding the overlapping of cross-sections.

Channel roughness $k_{\mathrm{s}}$ was explicitly represented in both the one- and two-dimensional hydraulic models employed herein (see below) using the Darcy-Weisbach friction factor $f$ (e.g. Streeter, 1951). In this study roughness values were calculated based on particle-sizes (intermediate axis) of cobbles and boulders deposited on the bed of study reach, as measured at 31 discrete locations (Fig. 3) along the study reach. Care was taken to distinguish fluvially deposited materials from those particles derived from other processes, and only the former were measured until 40 particles were retained in each sample. The median and 84th percentile particle sizes were then estimated for each of the 31 sampling locations.

The final element of field data collection involved identification of palaeostage indicators (PSI) to infer the minimum flow elevation of the outburst event. A number of well-preserved PSI were found within the study reach (see Fig. 3 and Table 1). These included (1) fluvial (rounded) pebbles wedged into elevated cracks in the walls of the gorge (Baker, 1987; O'Connor and Baker, 1992); (2) distinctive sediment deposits (Jarrett, 1990; Pruess et al., 1998) including elevated flood bars and fluvial cobbles; and (3) slackwater deposits (Kochel and Baker, 1988) in locations of assumed flow separation (Fig. 3). When plotted on a long-profile of the study reach, the PSI can be used to estimate the water surface of the outburst event (Fig. 4). The degree of confidence that an individual PSI was actually submerged by the outburst event varies according to the nature of each individual piece of field evidence (Table 1). However, taken together the relatively large number of PSI, and their distribution along a consistent gradient, suggests that the reconstructed water surface (Fig. 4) is a reliable indicator of the minimum elevation of the outburst event.

\section{Flood reconstruction: one- versus two-dimensional shallow water modelling}

A general hydraulic model for floods in bedrock channels must account for free-surface and turbulence effects. The flow of pure water can be appropriately described by the incompressible, three-dimensional Navier-Stokes equations, together with an appropriate turbulence closure (Batchelor, 1967). The presence of a free-surface separating two immiscible phases, water and air, introduces an important complication in the mathematical model because it implies the need to account for the propagation of a discontinuity (Osher and Sethian, 1988). Moreover, such a complete model requires solving for the movement of the air phase or the extrapolation of the velocity field from the water to the atmosphere (Sethian and Smereka, 2003). To simplify the model, one can use an indicator function (instead of a level-set function) to capture the evolution of a thick interface and to include the surface tension effects as a volumetric force instead of as a surface force acting on the free-surface (Brackbill et al., 1992).

The long computational time required for the general model described above, together with the large number of numerical simulations to be performed (in order to study the sensitivity of the results to parameter variations), mean that we simplify the problem by making the following assumptions, namely that: vertical motions, diffusion of momentum due to viscosity and turbulence, wind effects and the Coriolis force are negligible, and the pressure is assumed hydrostatic. With these assumptions the two-dimensional shallow water equations are obtained by depthaveraging the Navier-Stokes equations. They express the conservation of mass and momentum as

$$
\frac{\partial \mathbf{U}}{\partial t}+\frac{\partial \mathbf{F}}{\partial \boldsymbol{x}}(\mathbf{U})+\frac{\partial \mathbf{G}}{\partial \boldsymbol{y}}(\mathbf{U})=\mathbf{S}(\boldsymbol{x}, \boldsymbol{y}, \mathbf{U}) \text {, }
$$

in which

$$
\begin{aligned}
& \mathbf{U}=(h, u h, v h)^{\top}, \\
& \mathbf{F}=\left[u h, \frac{(u h)^{2}}{h}+\frac{g h^{2}}{2}, u v h\right]^{\top}, \\
& \mathbf{G}=\left[v h, u v h, \frac{(v h)^{2}}{h}+\frac{g h^{2}}{2}\right]^{\top},
\end{aligned}
$$




\section{Outburst Reach in the Ferpècle Valley, Switzerland}

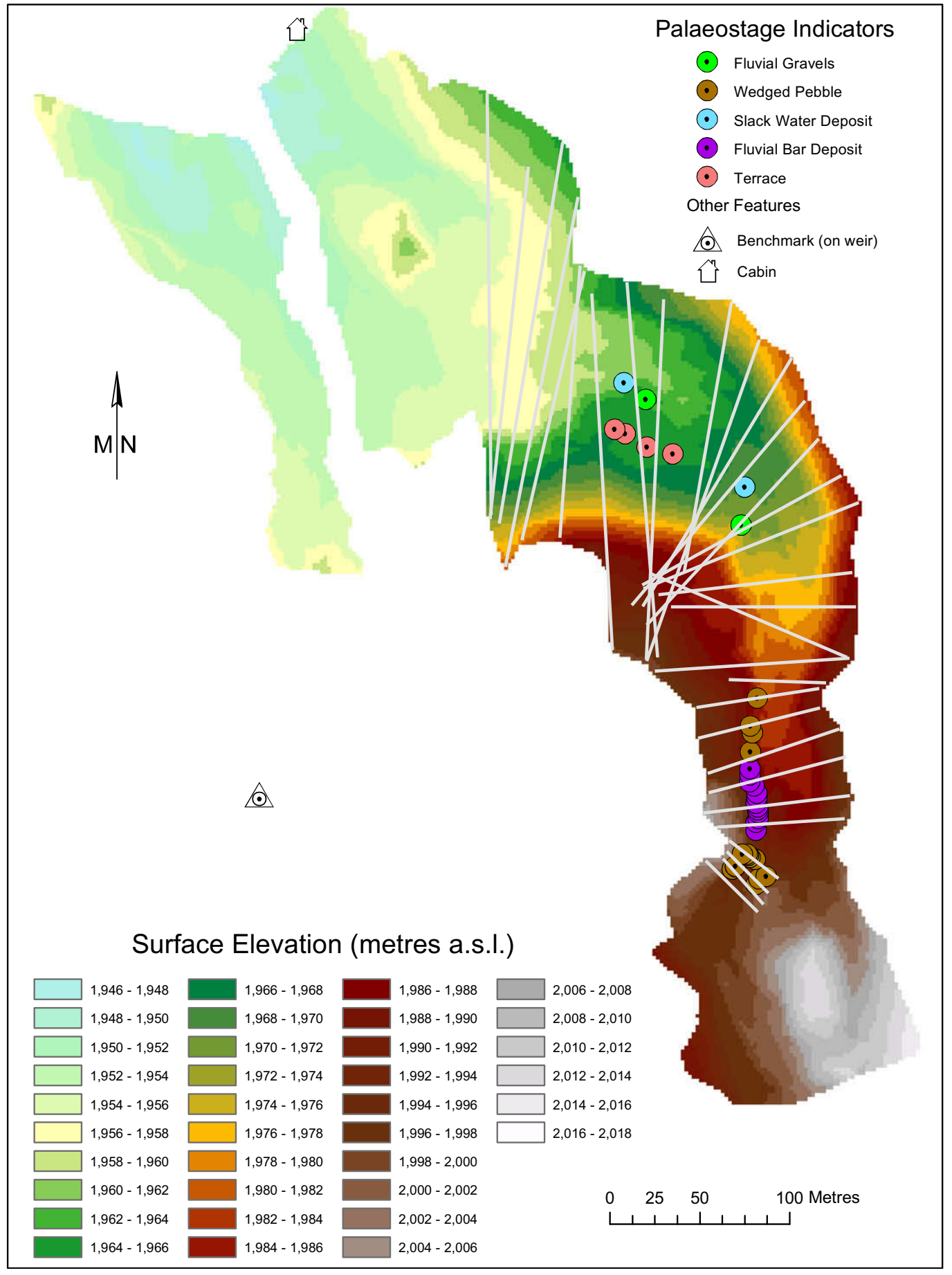

Figure 3 Elevation model of the study reach based on the topographic survey data. The locations of the 31 bed-material sampling transects (light-grey lines) and palaeostage indicators are also shown. The benchmark is located on a weir at the northern edge of the lake shown in Fig. 1b.

where $t$ is the time, $x$ and $y$ are the coordinates along the horizontal plane, $h$ is the depth of the water measured along the vertical coordinate $z, u$ and $v$ are the depth-averaged velocities in the $x$ - and $y$ - directions, respectively, $g$ is the acceleration due to gravity, and the superscript ' $T$ ' denotes the transposed vector. The source terms in the momentum equation are the bed slopes $S_{0}$ and the dimensionless friction factor $S_{f}$ along the two coordinate directions,

$S=\left[0, g h\left(S_{0 x}-S_{f x}\right), g h\left(S_{0 y}-S_{f y}\right)\right]^{\top}$, 
Table 1 Overview of palaeostage indicators (PSI) in the study reach showing their location and elevation with an assessment of the degree of confidence that the indicator was deposited by the outburst event

\begin{tabular}{|c|c|c|c|c|}
\hline Code & Type & Distance downvalley (m) & Elevation (m a.s.l.) & Confidence \\
\hline PW9 & Wedged pebble & 17.688 & 1998.53 & High \\
\hline PW10 & Wedged pebble & 20.94 & 1997.18 & High \\
\hline PW11 & Wedged pebble & 24.79 & 1996.68 & Medium \\
\hline PW8 & Wedged pebble & 15.23 & 1995.01 & Medium \\
\hline PW7 & Wedged pebble & 17.54 & 1997.71 & High \\
\hline PW6 & Wedged pebble & 17.62 & 1997.40 & High \\
\hline PW4 & Wedged pebble & 27.81 & 1992.25 & High \\
\hline PW3 & Wedged pebble & 26.74 & 1995.82 & Low \\
\hline PW2 & Wedged pebble & 26.92 & 1996.18 & High \\
\hline PW1 & Wedged pebble & 27.06 & 1997.00 & Low \\
\hline PW5 & Wedged pebble & 25.19 & 1998.97 & Medium \\
\hline BAR1.1 & Top of fluvial bar & 40.34 & 1993.28 & High \\
\hline BAR1.2 & Top of fluvial bar & 43.61 & 1993.03 & High \\
\hline BAR1.3 & Top of fluvial bar & 45.91 & 1992.04 & High \\
\hline BAR1.4 & Top of fluvial bar & 62.46 & 1991.51 & High \\
\hline BAR1.5 & Top of fluvial bar & 64.16 & 1991.29 & High \\
\hline BAR1.6 & Top of fluvial bar & 65.57 & 1990.38 & High \\
\hline BAR1.7 & Top of fluvial bar & 67.76 & 1990.11 & High \\
\hline BAR1.8 & Top of fluvial bar & 70.69 & 1989.63 & High \\
\hline BAR1.9 & Top of fluvial bar & 73.30 & 1989.45 & High \\
\hline BAR1.10 & Top of fluvial bar & 77.49 & 1988.83 & High \\
\hline BAR1.11 & Top of fluvial bar & 80.11 & 1988.82 & High \\
\hline BAR1.12 & Top of fluvial bar & 83.77 & 1987.79 & High \\
\hline BAR1.13 & Top of fluvial bar & 87.18 & 1987.53 & High \\
\hline PW12 & Wedged pebble & 96.38 & 1986.54 & High \\
\hline PW13 & Wedged pebble & 106.71 & 1984.53 & High \\
\hline PW14 & Wedged pebble & 110.76 & 1986.81 & High \\
\hline PW15 & Wedged pebble & 125.54 & 1983.66 & High \\
\hline FG1 & Fluvially deposited cobbles & 229.09 & 1972.53 & High \\
\hline SW2 & Slackwater deposit (separation zone) & 248.05 & 1969.47 & High \\
\hline FD1 & Bar top deposit & 301.73 & 1965.43 & Medium \\
\hline FD2 & Bar top deposit & 316.33 & 1964.75 & Medium \\
\hline FG1 & Fluvially deposited cobbles & 328.52 & 1965.78 & High \\
\hline SW1 & Slackwater deposit (separation zone) & 336.74 & 1963.87 & High \\
\hline FD1 & Bar top deposit & 330.48 & 1964.27 & Medium \\
\hline FD2 & Bar top deposit & 343.37 & 1962.81 & Medium \\
\hline
\end{tabular}

in which

$S_{0 x}=-\frac{\partial S}{\partial x}, \quad S_{0 y}=-\frac{\partial S}{\partial y}$

where $S(x, y)$ is the vertical coordinate of the bed.

To compute the friction term, $\mathbf{S}_{\mathrm{f}} \equiv\left(\tau_{\mathrm{b}} / \rho \mathrm{gh}\right)$, where $\tau_{\mathrm{b}}$ is the bed shear stress and $\rho$ the fluid density, we use the Darcy-Weisbach friction factor $f$ (Streeter, 1951), so that $\mathrm{S}_{\mathrm{f}}$ may be written as

$\mathrm{S}_{\mathrm{f}} \equiv\left(\mathrm{S}_{\mathrm{fx}}, \mathrm{S}_{\mathrm{fy}}\right)^{\top} \equiv \frac{f}{8 g} \frac{\sqrt{u^{2}+v^{2}}}{h}(u, v)^{\top}$.

The factor $f$ is a function of the local Reynolds number, based on the velocity magnitude and the water height $h$, and the relative roughness of the bed. In particular, we use the Serghides equation (Serghides, 1984) to explicitly estimate $f$, and reduce the computational time required by solving the implicit Colebrook-White expression (Colebrook, 1939).
The two-dimensional shallow water model (1)-(7), together with appropriate initial and boundary conditions, is discretized by a finite volume method based on the Harten-Lax-van Leer contact wave (HLLC) solver implemented in the Open Source project DASSFLow (Honnorat et al., 2007a; Honnorat et al., 2007b). The two-dimensional mesh is built using approximately $10^{5}$ triangular cells with an average element size of $0.75 \mathrm{~m}$. To satisfy the Courant-Friedrichs-Lewy (CFL) stability condition (LeVeque, 2002), required by the forward Euler scheme in time, the time step is calculated and adjusted during the numerical simulation. The CFL number is fixed to 0.45 . The water height inferred from the PSIs at the inlet $(3.3-6 \mathrm{~m})$ and the expected flow discharge give rise to a supercritical inflow regime. Therefore, three inflow boundary conditions (BCs) must be imposed using the characteristic variables method (Blayo and Debreu, 2005). For these inflow BCs, a supercritical flow field is also found at the model outlet and thus no physical outflow BCs are to be applied. How- 


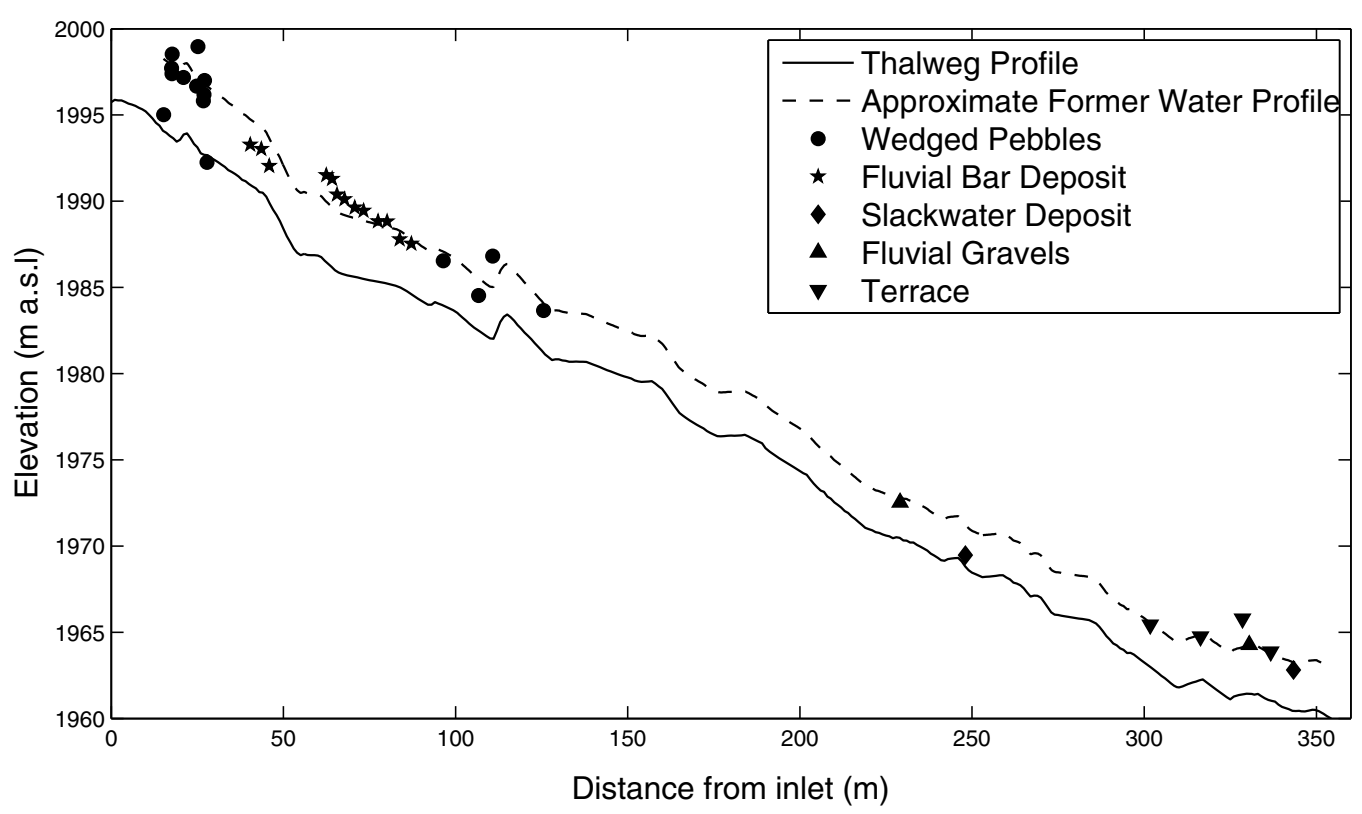

Figure 4 Thalweg profile of the study reach showing the elevations of the palaeostage indicators and reconstructed palaeoflood water surface profile.

ever, three additional numerical BCs are required by the numerical scheme. We adopt the characteristic variable extrapolation method (CVE) as the outflow condition. The zero-order version of the CVE method can be adopted for the first-order numerical scheme used by DASSFLOW, this is equivalent to imposing homogeneous Neumann BCs for both the water height and the velocity field. The physical meaning of the homogeneous Neumann boundary conditions is that of a uniform state at the outlet characterized by the flow coming from upstream.

For quasi-symmetric channels with a gradual variation of the cross-section and smooth streamwise curvature, one can adopt a simpler model. In fact, many hydraulic situations can be described by means of a one-dimensional model (Fig. 5) and, as described in our introduction to this paper, such approaches have routinely been employed in palaeoflood studies. The equations for the one-dimensional model can be derived from mass and momentum control volume analysis as in Cunge et al. (1980), giving: $\frac{\partial \mathbf{U}}{\partial t}+\frac{\partial \mathbf{F}}{\partial \boldsymbol{x}}(\boldsymbol{x}, \mathbf{U})=\mathbf{S}(\boldsymbol{x}, \mathbf{U})$

with

$\mathbf{U}=(\boldsymbol{A}, \boldsymbol{Q})^{\top}$,

$\mathbf{F}=\left(Q, \frac{Q^{2}}{A}+g l_{1}\right)^{\top}$,

$\mathbf{S}=\left[0, g I_{2}+g A\left(S_{0}-S_{f}\right)\right]^{\top}$

in which $A$ is the wetted cross-sectional area and $Q \equiv u A$ is the two-dimensional flow rate. The term $l_{1}$ represents a cross-sectional hydrostatic pressure force,

$I_{1}(x, A)=\int_{0}^{h(x, A)}[h(x, A)-\eta] \sigma(x, \eta) \mathrm{d} \eta$,

in terms of the surface water level $h(x, A)$ and the width $\sigma(\boldsymbol{x}, \eta)$,

$\sigma(x, \eta)=\frac{\partial A(x, t)}{\partial \eta}$

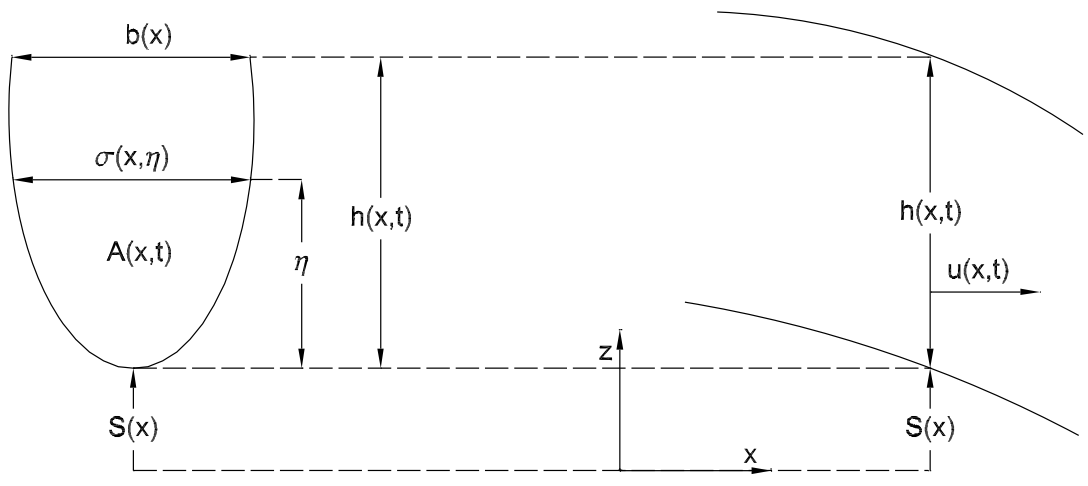

Figure 5 Coordinates and sketch of an ideal one-dimensional open channel. The cross-section and longitudinal profile is plotted on the left and right hand side of the diagram, respectively. 
and $I_{2}$ is the component of the pressure force in the direction of the main stream due to the reaction of the walls in case of variations in shape along this direction,

$I_{2}(\boldsymbol{x}, \boldsymbol{A})=\int_{0}^{h(x, A)}[h(\boldsymbol{x}, \boldsymbol{A})-\eta] \frac{\partial \sigma(\boldsymbol{x}, \eta)}{\partial \boldsymbol{x}} \mathrm{d} \eta$.

The magnitude of this force depends on the cross-sectional variation for a constant depth. It is important to note that the validity of this approach is linked to the hypothesis of gradual variation. If sudden expansions or contractions take place, the approach is not valid. Moreover, to account with precision for this pressure component, the streamwise gradient of the width is required.

Finally, the one-dimensional friction term required to close the model reduces to

$S_{\mathrm{f}}=\frac{f}{8 g} \frac{|u| u}{R_{\mathrm{h}}}, \quad R_{\mathrm{h}} \equiv \frac{A}{P}$,

where the local Reynolds number required to compute $f$ is now based on the velocity $u$, the hydraulic radius $R_{\mathrm{h}}$ of the channel and the relative roughness height of the bed, as discussed previously, and $P$ represents the wetted perimeter.

The validity of the one-dimensional model can be analysed a priori via dimensional analysis (see Appendix A for details). The first source of error is due to neglecting the contribution of the transversal velocity to the global momentum balance, and is of order $\mathrm{O}\left(B^{2} / L^{2}\right)$ (where $B$ is a characteristic channel width and $L$ is a characteristic longitudinal length). From the PSIs the typical channel width $B \approx 40 \mathrm{~m}$, whereas the longitudinal length scale $L \approx$ $360 \mathrm{~m}$. Thus, errors incurred by considering just the normal velocity $u$ and neglecting $v$ are around $1.2 \%$. The second source of error comes from the Cartesian coordinates used in the deduction of the one-dimensional Saint-Venant equations, and is of order $\mathrm{O}\left(R_{\mathrm{h}} / R\right)$ (where $R$ is the characteristic radius of the bend). The elevation model of the study reach (see Fig. 3) shows two main bends: the first is located between the inlet and the fluvial bar deposit, with $R \approx 100 \mathrm{~m}$; the next occupies the rest of the reach with $R \approx 300 \mathrm{~m}$. The topography of the study reach together with the water surface elevation inferred from the PSIs allows an objective quantification of the hydraulic radius $R_{\mathrm{h}}$. In the first reach, the maximum hydraulic radius is $2.5 \mathrm{~m}$, while downstream it is $2.1 \mathrm{~m}$. Thus, the maximum error associated with the use of Cartesian coordinates is of the order $2.5 \%$. This suggests that a one-dimensional approximation is not unreasonable in the case of the Mont Miné flood.

In recent years, the numerical solution of the shallow water equations in channels with irregular geometry has usually been undertaken using Riemann solvers, which require a correct treatment of the source terms involving the gradients of channel depth and width (Vázquez-Cendón, 1999). This tendency is well justified to ensure the numerical scheme conserves mass and momentum, in the accurate computation of hydraulic jumps and the absence of spurious oscillations (e.g. LeVeque, 2002). However, the one-dimensional hydraulic characteristics of outburst floods used to be determined via application of step-backwater flow models (Davidian, 1984) such as those implemented in HEC-RAS (Hydrologic Engineering Centre, 2001). Nowadays these methods have been superseded by more sophisticated and accurate procedures (Wright, 2005). Furthermore, in using the step-backwater modelling technique there is potential for uncertainty in modelling energy losses because it is difficult to select appropriate values of the expansion/contraction coefficients, and on occasions a special effort is needed to set the simulation tolerance options to obtain a stable simulation condition (e.g. Alho and Aaltonen, 2008).

For these reasons, we employ an upwind total variation diminishing (TVD) method (e.g. LeVeque, 2002), second-order accurate in both space and time, with a semi-implicit and upwind treatment of the source terms. Eq. (8) is solved numerically with the same technique as employed by Bohorquez et al. (2008) for a uniform grid with mesh size $\Delta x=0.36 \mathrm{~m}$. As in the two-dimensional case the integration time step is limited by a CFL type restriction, and the same CFL value is applied (CFL $=0.45)$. The number of physical boundary conditions and the way of imposing them depends, as in the two-dimensional approach, on the flow regime at the boundaries. The subcritical or supercritical character of the flow is determined by the Froude number Fr, that in its one-dimensional version reads (see, for instance, Cunge et al., 1980):

$F r \equiv \frac{u}{c}=\frac{Q / A(h)}{\sqrt{g A(h) / b(h)}}$

where $c$ is the celerity of the infinitesimal surface wave and $b$ is the channel width for a given water depth $h$. In the numerical simulations that follow (see next section) the inlet has been located at the downstream distance $x=15 \mathrm{~m}$, the outlet at $x=360 \mathrm{~m}$, and the flow discharge was progressively increased from the critical value associated with water heights derived from the palaeostage evidence (i.e., from 3.3 to $6 \mathrm{~m}$ ). Hence, two physical inflow BCs are to be imposed. The CVE method has been correctly applied at the outlet since an outflow supercritical flow was found with the inflow BCs used. For simplicity we apply the firstorder version of the CVE method. Now, the first-order extrapolation does not imply an uniform outflow regime, although the physical meaning is the same as in the twodimensional case: the information is travelling from the interior spatial domain and therefore the outflow regime is determined from the solution inside the boundary.

However, in the two-dimensional flow, the Froude number $F r$ has a different expression (e.g. LeVeque, 2002)

$F r \equiv \frac{\|\mathbf{u}\|_{2}}{c}=\frac{\sqrt{u^{2}+v^{2}}}{\sqrt{g h}}$.

Taking into account the relation shown above, and imposing a uniform cross-sectional velocity profile, we found that the two-dimensional Froude number is always larger than the one-dimensional Froude number at the inflow cross-section. Therefore, the hydraulic parameters that actually govern the shallow water model are the bed roughness $k_{\mathrm{s}}$, inflow water height $h_{\mathrm{i}}$, and both the magnitude $Q$ and direction of the discharge.

The procedure to estimate the discharge of the outburst event using the one-dimensional shallow water model was as follows. Water surface profiles were calculated by fixing the water surface elevations at the upstream boundary of the reach, in accordance with values determined by 
extrapolation of the reconstructed water surface profile (Fig. 4). Each model was applied in a series of simulations in which flow discharge values were varied to generate simulated water surface profiles that bracketed the 'observed' flow profile. Further simulations, using refined estimates of flow discharge within the bracketed range, eventually allowed precise retrodiction of a flow discharge value that optimally matched the simulated and observed profiles. In all the simulations reported herein, the PSI data are not matched perfectly by a single flow profile. Indeed, since some of the PSI (especially the wedged pebbles) are no doubt in part constrained by the location of cracks and fissures in the bedrock, so they may not always indicate the maximum water level (Carling and Grodek, 1994) and it is not appropriate to force the water surface slope to match all the PSI exactly. Selection of the flow discharge value that optimally matched the field evidence was instead undertaken by comparison of the root-mean square (RMS) errors of simulated profiles.

For the two-dimensional modelling, the procedure used to estimate the palaeoflood flow discharge was largely similar to that employed for the one-dimensional modelling (i.e. simulations were conducted with a range of flow discharges iteratively until there was optimal fit between the simulated and observed water surface profiles), albeit with a minor difference. Specifically, unlike the one-dimensional modelling, where the water surface at each cross-section is assumed horizontal, simulated water surface elevations are free to adjust across each cross-section in the two-dimensional model. To facilitate the comparison between the one- and two-dimensional model results we employ crosssectionally averaged water surface profiles when fitting the outputs from the two-dimensional model to the observed data. The implications of this simplification are discussed in the next section where we highlight the differences in the optimally fitted (longitudinal) water surface profile arising when the two-dimensional water surface profiles are cross-sectionally averaged and when free surface effects are retained.

\section{Results and discussion}

In using the shallow water modelling technique there is potential for uncertainty in modelling energy losses because it is difficult to constrain the bed roughness $k_{\mathrm{s}}$. The appropriate selection of the upstream water height $h_{\mathrm{i}}$ and the main flow path (i.e., the one-dimensional axis) are additional sources of uncertainty. The effects of these uncertainties can be quantified by undertaking sensitivity analyses to determine how retrodicted flows vary over an appropriate range of specified coefficient values (Miller and Cluer, 1998). Thus, channel roughness and inflow water height were systematically varied, both in isolation and combination, across the full range of values thought to be appropriate for the modelled reach. The valid extent of the range for the water depth at the inflow location is established from the numerous PSIs placed there, $h_{\mathrm{i}}=3.3-6 \mathrm{~m}$, whereas the bed roughness of the study reach was found to vary in the range $k_{\mathrm{s}}=0.8-1.4 \mathrm{~m}$, based on the observed bed-material particle sizes.

All the results presented below are based on the steady state attained when the initially dry valley is inundated by the flood wave. As described in the previous section, the flood wave is fully characterised in terms of the upstream boundary conditions, which are here given steady fixed values. Hence, although the boundary conditions at the inlet are steady, our numerical simulations are unsteady and by late time in the simulation they achieve a steady state. It should be pointed out that the water levels during the one- and two-dimensional filling process are always lower than the final, steady, water levels. Therefore, the maximum water levels that must be employed to compute the RMS error are (in the present case) the steady state water levels.

\section{Sensitivity analyses}

Fig. 6 shows RMS errors for the simulated profiles using the one-dimensional Saint-Venant equations (cases a, c and e) and the two-dimensional model (cases b, $d$ and $f$ ). A total of 100 cross-sections uniformly distributed along the onedimensional channel axis were considered in the RMS error computation. The inflow water height having the lowest $R M S$ error in the one-dimensional simulations is $h_{\mathrm{i}}=5.5 \mathrm{~m}$, independent of the values taken by the flow rate $Q$ and the bed roughness $k_{s}$. The optimum water height at the inlet inferred from the cross-sectional averaged, two-dimensional simulations is $h_{\mathrm{i}}=4.45 \mathrm{~m}$. This finding justifies the range over which the $h_{i}$ parameter was varied during the flood reconstruction procedure. Furthermore, these optimum values are within the physical range defined by the PSIs at the inlet. Based on the particle sizes estimated from the bed-material samples on the bed of study reach, the second input parameter in the shallow water models (the bed roughness parameter $k_{\mathrm{s}}$ ) was varied in the range $0.8<k_{\mathrm{s}}<1.4 \mathrm{~m}$. Both the one- and two-dimensional averaged results shown that the bed roughness with the lowest $R M S$ error is $k_{\mathrm{s}}=0.8 \mathrm{~m}$. Thus, although from the mathematical point of view, it seems appropriate to continue decreasing this value to find one with a lower RMS error, this physical value was accepted.

The optimum discharge, defined by the minimum of the RMS error curves commented on above, is summarized in Tables 2 and 3 as a function of bed roughness $k_{\mathrm{s}}$ and upstream water height $h_{\mathrm{i}}$. Optimum values of input parameters in the one-dimensional Saint-Venant model (i.e. bed roughness, inflow water height and flow rate) are $k_{\mathrm{s}}=0.8 \mathrm{~m}, h_{\mathrm{i}}=5.5 \mathrm{~m}$ and $Q=557 \mathrm{~m}^{3} \mathrm{~s}^{-1}$. These values differ from the optimum values derived from the cross-sectional averaged, twodimensional model: $k_{\mathrm{s}}=0.8 \mathrm{~m}, h_{\mathrm{i}}=4.45 \mathrm{~m}$ and $Q=454 \mathrm{~m}^{3} \mathrm{~s}^{-1}$. This difference amounts to a $22.7 \%$ discrepancy between the steady flow discharge estimated using the one-dimensional versus two-dimensional models. The reason for this discrepancy is highlighted in Fig. 8, which shows the one-dimensional and the averaged two-dimensional water surface profile for these particular cases. Both profiles are nearly indistinguishable along the upper, $x<50 \mathrm{~m}$, and lower reach, $x>110 \mathrm{~m}$. However, the two models diverge in the region $50<x<110 \mathrm{~m}$ due to the presence of a recirculation zone, reproduced by the two-dimensional model. In terms of the range of retrodicted discharges, Fig. 6 and Tables 2 and 3 indicate that flow discharge estimates derived from the onedimensional modelling vary between 429 and $557 \mathrm{~m}^{3} \mathrm{~s}^{-1}$, 

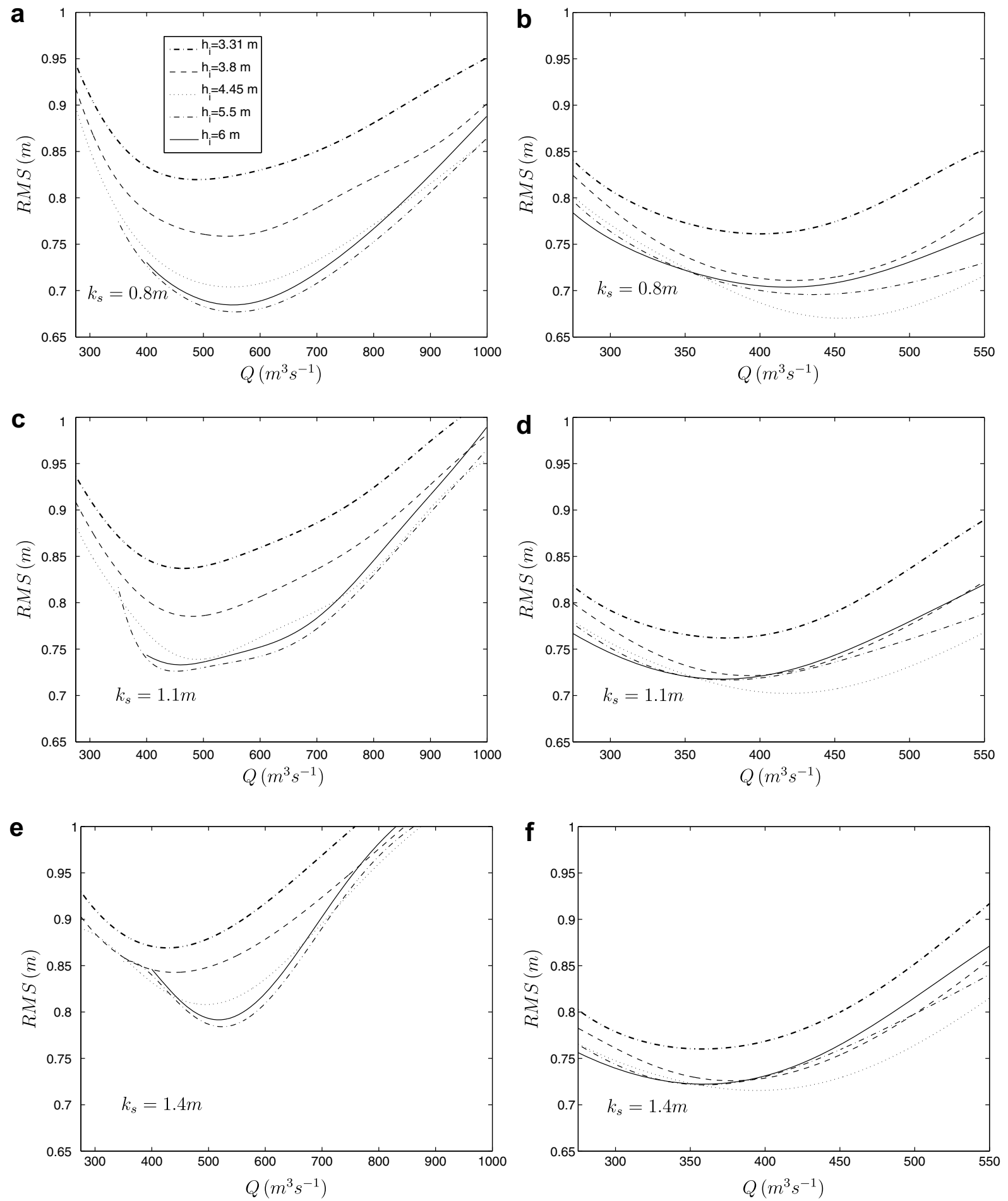

Figure 6 RMS error curves as a function of flow discharge for several bed roughness $\left(k_{\mathrm{s}}\right)$ and inflow water height $\left(h_{\mathrm{i}}\right)$ values. In the left-hand column (cases a, c and e) the RMS error was computed by comparing the one-dimensional water surface elevation with respect to the reconstructed palaeoflood water surface profile. Cases $\mathrm{b}, \mathrm{d}$ and $\mathrm{f}$ (right-hand column) show the RMS errors calculated in the same way using the cross-sectionally averaged two-dimensional water surface profile. Note the difference in the abscissa scale between the left- and right-hand columns.

whereas flow rates derived from the cross-sectional averaged, two-dimensional modelling are confined in a narrower (and lower) range of $358-454 \mathrm{~m}^{3} \mathrm{~s}^{-1}$.

The results of the sensitivity analysis discussed above can be presented in terms of percentage errors in the estimation of the flow discharge. In the one-dimensional case, the error range is $\pm 43 \%$, whereas the cross-sectional averaged, twodimensional simulations exhibit a lower sensitivity of $\pm 24 \%$. These values are similar to the results of Wohl (1998) who employed one-dimensional modelling in canyon 
Table 2 Each cell lists the optimum discharge $Q\left(\mathrm{~m}^{3} \mathrm{~s}^{-1}\right)$ (left) and the corresponding RMS (m) error (right), respectively, from Fig. 6 (cases a, c and e) for the bed roughness $k_{\mathrm{s}}=0.8,1.1,1.4 \mathrm{~m}$ and the water height $h_{\mathrm{i}}=3.31,3.8,4.45,5.5,6 \mathrm{~m}$

\begin{tabular}{|c|c|c|c|c|c|c|c|c|c|c|}
\hline \multirow{2}{*}{$k_{\mathrm{s}}$} & \multicolumn{10}{|l|}{$h_{\mathrm{i}}$} \\
\hline & \multicolumn{2}{|c|}{3.31} & \multicolumn{2}{|l|}{3.8} & \multicolumn{2}{|l|}{4.45} & \multicolumn{2}{|l|}{5.5} & \multicolumn{2}{|l|}{6} \\
\hline 0.8 & 489 & 0.820 & 542 & 0.759 & 549 & 0.704 & 557 & 0.677 & 553 & 0.684 \\
\hline 1.1 & 465 & 0.837 & 481 & 0.785 & 490 & 0.739 & 452 & 0.726 & 461 & 0.733 \\
\hline 1.4 & 429 & 0.869 & 441 & 0.843 & 496 & 0.808 & 525 & 0.784 & 519 & 0.792 \\
\hline
\end{tabular}

Table 3 Each cell lists the optimum discharge $Q\left(\mathrm{~m}^{3} \mathrm{~s}^{-1}\right)$ (left) and the corresponding $R M S$ (m) error (right), respectively, from Fig. 6 (cases b, d and f) for the bed roughness $k_{\mathrm{s}}=0.8,1.1,1.4 \mathrm{~m}$ and the water height $h_{\mathrm{i}}=3.31,3.8,4.45,5.5,6 \mathrm{~m}$

\begin{tabular}{|c|c|c|c|c|c|c|c|c|c|c|}
\hline \multirow{2}{*}{$k_{\mathrm{s}}$} & \multicolumn{10}{|l|}{$h_{\mathrm{i}}$} \\
\hline & \multicolumn{2}{|c|}{3.31} & \multicolumn{2}{|l|}{3.8} & \multicolumn{2}{|l|}{4.45} & \multicolumn{2}{|l|}{5.5} & \multicolumn{2}{|l|}{6} \\
\hline 0.8 & 400 & 0.761 & 422 & 0.711 & 454 & 0.670 & 436 & 0.696 & 418 & 0.704 \\
\hline 1.1 & 378 & 0.762 & 392 & 0.722 & 419 & 0.702 & 378 & 0.717 & 375 & 0.718 \\
\hline 1.4 & 358 & 0.760 & 378 & 0.726 & 395 & 0.716 & 359 & 0.722 & 359 & 0.722 \\
\hline
\end{tabular}

Table 4 Each cell lists the optimum discharge $Q\left(\mathrm{~m}^{3} \mathrm{~s}^{-1}\right)$ (left) and the corresponding RMS (m) error (right), respectively, from Fig. 7 (cases a, c and e) for the bed roughness $k_{\mathrm{s}}=0.8,1.1,1.4 \mathrm{~m}$ and the water height $h_{\mathrm{i}}=3.31,3.8$, $4.45 \mathrm{~m}$

\begin{tabular}{|c|c|c|c|c|c|c|}
\hline \multirow[t]{2}{*}{$k_{\mathrm{s}}$} & \multicolumn{6}{|l|}{$h_{\mathrm{i}}$} \\
\hline & 3.31 & & 3.8 & & 4.45 & \\
\hline 0.8 & 484 & 1.053 & 505 & 1.047 & 549 & 1.115 \\
\hline 1.1 & 469 & 1.046 & 497 & 1.049 & 528 & 1.132 \\
\hline 1.4 & 465 & 1.045 & 501 & 1.056 & 525 & 1.152 \\
\hline
\end{tabular}

rivers with gradual channel gradients $(0.01 \mathrm{~m} / \mathrm{m})$, but they are smaller than those reported by Kidson et al. (2006) $( \pm 51 \%$ from their Table 5$)$.

The implications of using an approximate former water profile fitted to the PSI data, to compute RMS errors, and to derive the optimum flood discharge, can be evaluated by calculating the latter using only individual PSI values. When the analysis is performed in one-dimension, RMS errors can be computed at each of the 36 specific longitudinal coordinates where the PSIs are found, comparing the water height inferred from each of them with the simulated data.

Table 5 Each cell lists the optimum discharge $Q\left(\mathrm{~m}^{3} \mathrm{~s}^{-1}\right)$ (left) and the corresponding RMS (m) error (right), respectively, from Fig. 7 (cases $b, d$ and $f$ ) for the bed roughness $k_{\mathrm{s}}=0.8,1.1,1.4 \mathrm{~m}$ and the water height $h_{\mathrm{i}}=3.8,4.45,5.5$, $6 \mathrm{~m}$

\begin{tabular}{|c|c|c|c|c|c|c|c|c|}
\hline \multirow[t]{2}{*}{$k_{\mathrm{s}}$} & \multicolumn{8}{|l|}{$h_{\mathrm{i}}$} \\
\hline & 3.8 & & 4.45 & & 5.5 & & 6 & \\
\hline 0.8 & 445 & 2.067 & 497 & 2.306 & 740 & 2.208 & 818 & 2.231 \\
\hline 1.1 & 397 & 2.543 & 504 & 2.294 & 770 & 2.190 & 810 & 2.234 \\
\hline 1.4 & 389 & 2.517 & 548 & 2.275 & 778 & 2.155 & 853 & 2.243 \\
\hline
\end{tabular}

Results for the cross-sectional averaged, two-dimensional simulations are summarized in Fig. 7 and Table 4, excluding the curves with $h_{\mathrm{i}}=5.5$ and $6 \mathrm{~m}$ whose aspect is strongly non linear, thereby preventing the identification of any minimum. Furthermore, the right branch of the curves becomes distorted for flow discharges greater than the optimum in the particular cases $h_{i}=3.31$ and $3.8 \mathrm{~m}$. Optimum discharges in Table 4 deviate from the previous values (Table 3 ) by an average of $26 \%$, where the maximum and minimum differences are found to be $20 \%$ and $33 \%$, respectively, highlighting the importance of using only the individual PSI data, not a water profile curve fitted to the PSI data by regression.

To include two-dimensional effects in the reconstruction procedure, which enriches the description of real floods, three-dimensional locations of PSIs are necessary to compute the RMS errors. The right column in Fig. 7 shows these two-dimensional error curves have a more chaotic aspect: they present several local minimums for different values of the flow discharge $Q$, the aspect of the curve is different for several inflow water heights $h_{\mathrm{i}}$, and the sensitivity to changes in the bed roughness $k_{\mathrm{s}}$ is less than to changes in the water height at the inlet $\left(h_{i}\right)$. These problems are due to the specific distribution of the current PSIs, which are mostly located along the inner bank and which are grouped in specific regions of the study reach, which makes it difficult to recreate a former water surface. In fact, the optimum flow discharges vary over a wide range as a function of the bed roughness $k_{\mathrm{s}}$ and inflow water height $h_{\mathrm{i}}$ : from $Q=389$ to $853 \mathrm{~m}^{3} \mathrm{~s}^{-1}$, see Table 5 . This is not surprising: when there are not enough PSIs to reconstruct a proper, former water surface, the flow discharges are poorly constrained.

\section{Retrodicted flood characteristics}

As discussed previously, the main drawback of the onedimensional Saint-Venant equations is that they are unable to represent cross-sectional variations in water surface elevations. However, in the presence of sharp bends and steep slopes, the free surface may exhibit significant deforma- 

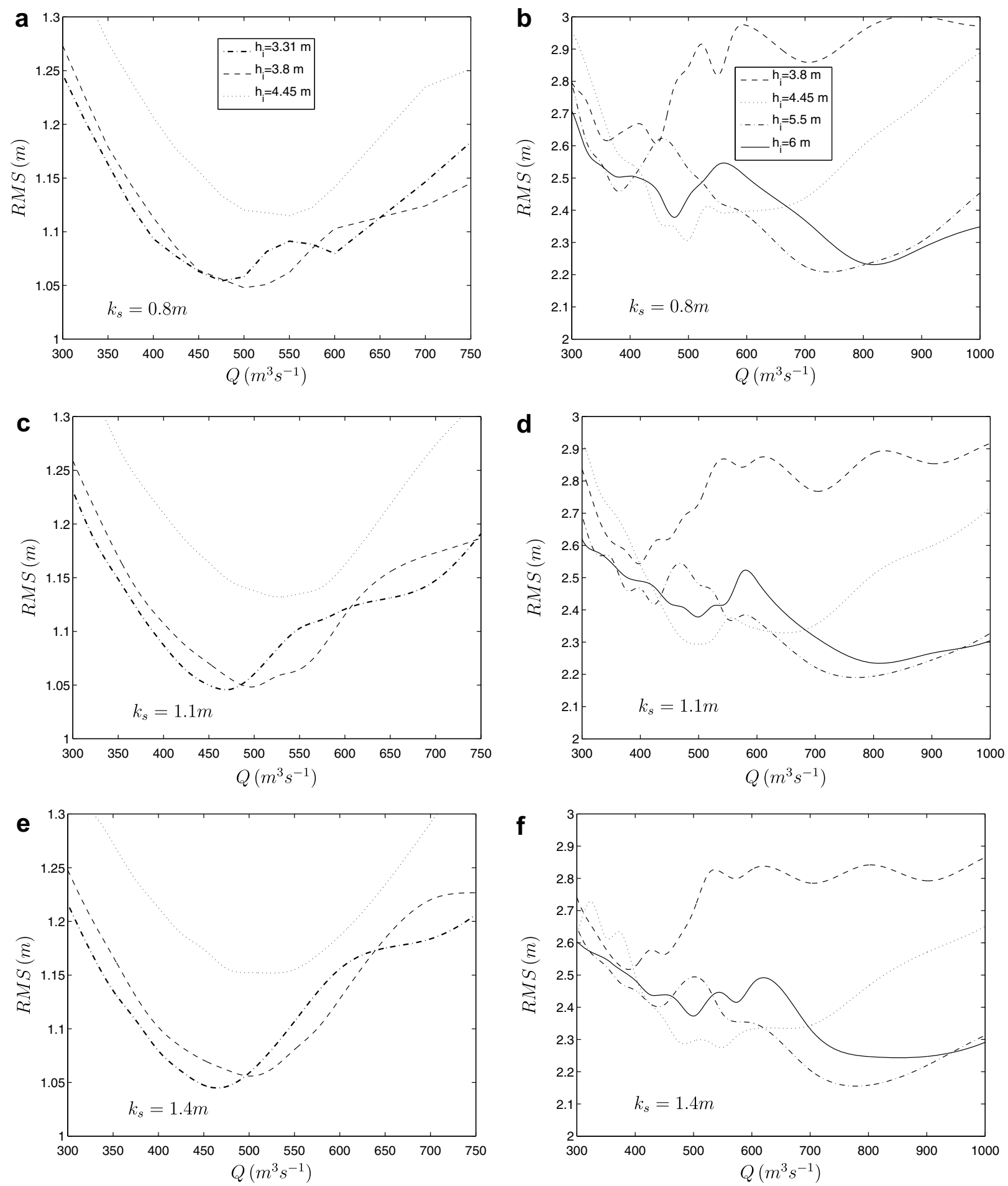

Figure 7 RMS error curves as a function of flow discharge for several bed roughness $\left(k_{\mathrm{s}}\right)$ and inflow water heights $\left(h_{\mathrm{i}}\right)$ values. In the left- and right-hand column RMS errors were computed from the averaged two-dimensional water height and the two-dimensional water surface, respectively, evaluating the errors at the specific locations where the 36 palaeostage indicators were found.

tion. As a matter of fact, Fig. 9 shows large differences between the one- and two-dimensional water surface profiles at most of the cross-sections indicated in Fig. 8a. For example, the largest errors of the one-dimensional water surface elevation with respect to the two-dimensional prediction are $3.55,2.83,3.38$ and $1.9 \mathrm{~m}$ in sections $B, D, E$ and $F$, respectively. Just when water starts to flow along the inlet, the channel narrows on the left bank, as noted when comparing the survey elevation A and B. The photograph of the inlet of the gorge (Fig. 2) clearly displays this constraint, which forces both the water height and the flow velocity to increase on the left and right bank, respectively. So the 
wedged pebbles located in the upstream part of the reach are indeed covered by water in the simulations. The effects of the inlet of the gorge are still present in cross-sections $\mathrm{C}-\mathrm{E}$, where water tends to super-elevate on the right bank. Thus, the top of the fluvial bar situated downstream is not submerged by the simulated flood (see, for instance, subplot E). Far enough from the inlet, i.e. at cross-section $F$, the water surface flattens and attains an elevation high enough to cover the wedged pebbles. Fluvial gravels, terrace and slack water deposits are also clearly submerged by the reconstructed flood, as shown in subsets $\mathrm{G}-\mathrm{J}$. Finally, note the agreement between the one-dimensional and aver- aged two-dimensional results, which is good $(\leqslant 0.38 \mathrm{~m})$ except in sections $B, D, E$ and $F$. The differences found in the results are clearly justified by the two-dimensional constraints imposed by the survey, which routes the water through a specific flow path not easy to predict a priori, by the presence of island and a recirculation zone.

The description of the flow characteristics given above can be visualized more clearly using a plan view of both the flow depth and depth-averaged velocity field (Figs. 10 and 11 , respectively). The water height along the inlet left bank, due to the shape of the gorge, is readily appreciated for $y<15 \mathrm{~m}$. Consequently, the flow is routed to the right,
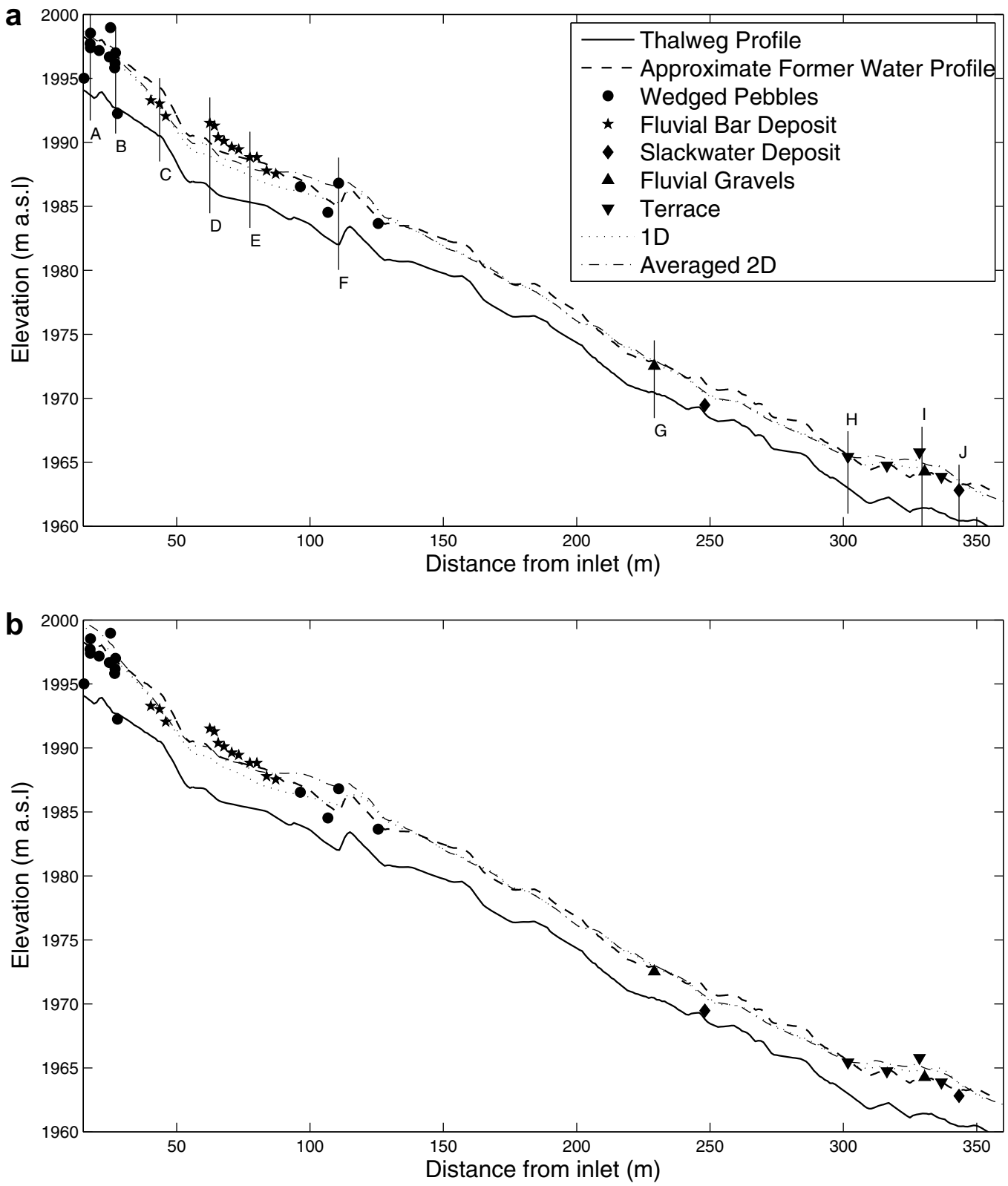

Figure 8 Thalweg profile of the study reach showing the elevations of palaeostage indicators, reconstructed palaeoflood water surface profile, one-dimensional and cross-sectionally averaged two-dimensional simulated water surface profile for the case with the minimum RMS error in (a) Table 2 and (b) Table 3. This is (a) $k_{\mathrm{s}}=0.8 \mathrm{~m}, h_{\mathrm{i}}=4.45 \mathrm{~m}, Q=450 \mathrm{~m}^{3} \mathrm{~s}^{-1}$ and (b) $k_{\mathrm{s}}=0.8 \mathrm{~m}$, $h_{\mathrm{i}}=5.5 \mathrm{~m}, Q=550 \mathrm{~m}^{3} \mathrm{~s}^{-1}$. Details of the cross-sectional water surface profiles A-J, shown as vertical lines in (a), are shown in Fig. 9. 
as evident from the change of the streamline direction in the vicinity of the last wedged pebbles located at the inlet (see Fig. 11). Most, but not all, of the wedged pebbles at the inlet are therefore submerged by the simulated flood. Leaving the narrow path, velocity increases along the same direction (note the increment in the velocity magnitude and the straight shape of the streamline at $15<$ $y<40 \mathrm{~m}$ ). When the fluid reaches the right bank, it piles up over it, as previously noted in cross-sections C-E in Fig. 9, and hence the majority of fluvial bar deposits in the opposite bank are in fact not inundated by the retrodicted flood. Just a narrow stream flows near the fluvial bar deposits, creating an island. It should be pointed out that this feature persists in all the cases analysed here, independent of the values taken by the input parameters $k_{\mathrm{s}}, h_{\mathrm{i}}$ and $Q$, denoting the strong influence of the inlet of the gorge on
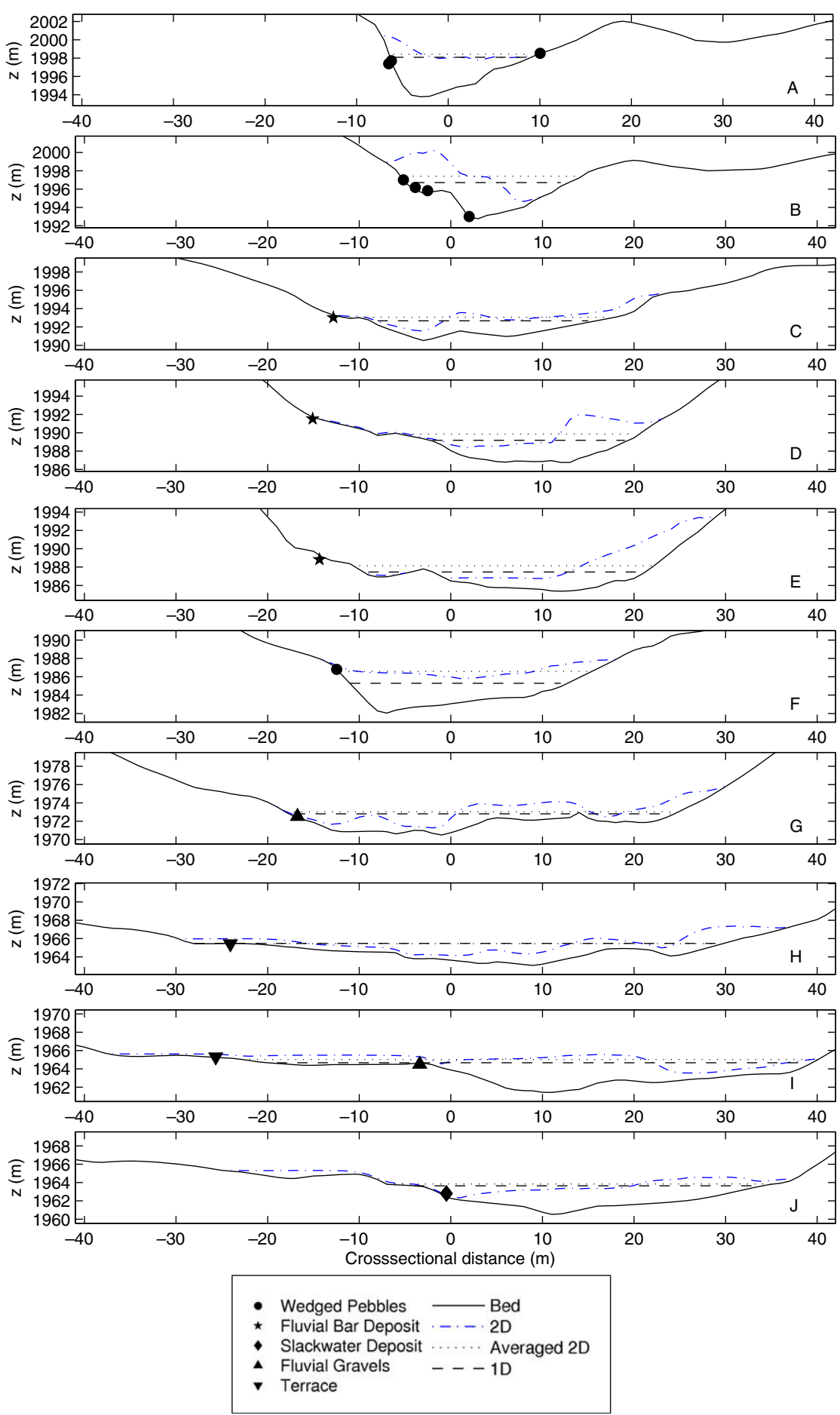

Figure 9 Cross-sectional geometry of the modelled water surface profiles at the cross-sections indicated in Fig. 8a, showing the relationship between the modelled profiles and the palaeostage indicators. 
the flood. Moreover, this finding also calls into question the origin of the so-called fluvial bar deposits preserved within this reach. Based on these simulations, these can be reinterpreted as being associated with other flood events coming from the older outflow channel (Fig. $1 \mathrm{~b}$ and on the left-hand side of Fig. 2). Behind the island a recirculation zone appears and inundates the wedged pebbles. The maximum velocity of the flow field, approximately $12 \mathrm{~m} / \mathrm{s}$, is located in the reach bordering the recirculation zone, where water is directed towards the opposite bank, and is much larger than the surface flow velocity of $3 \mathrm{~m} / \mathrm{s}$ (at an unknown location) estimated by an eyewitness (Hagen, 1944). Here the water now extends over the left bank, as can be noted by the location and proximity of the two streamlines in the re-

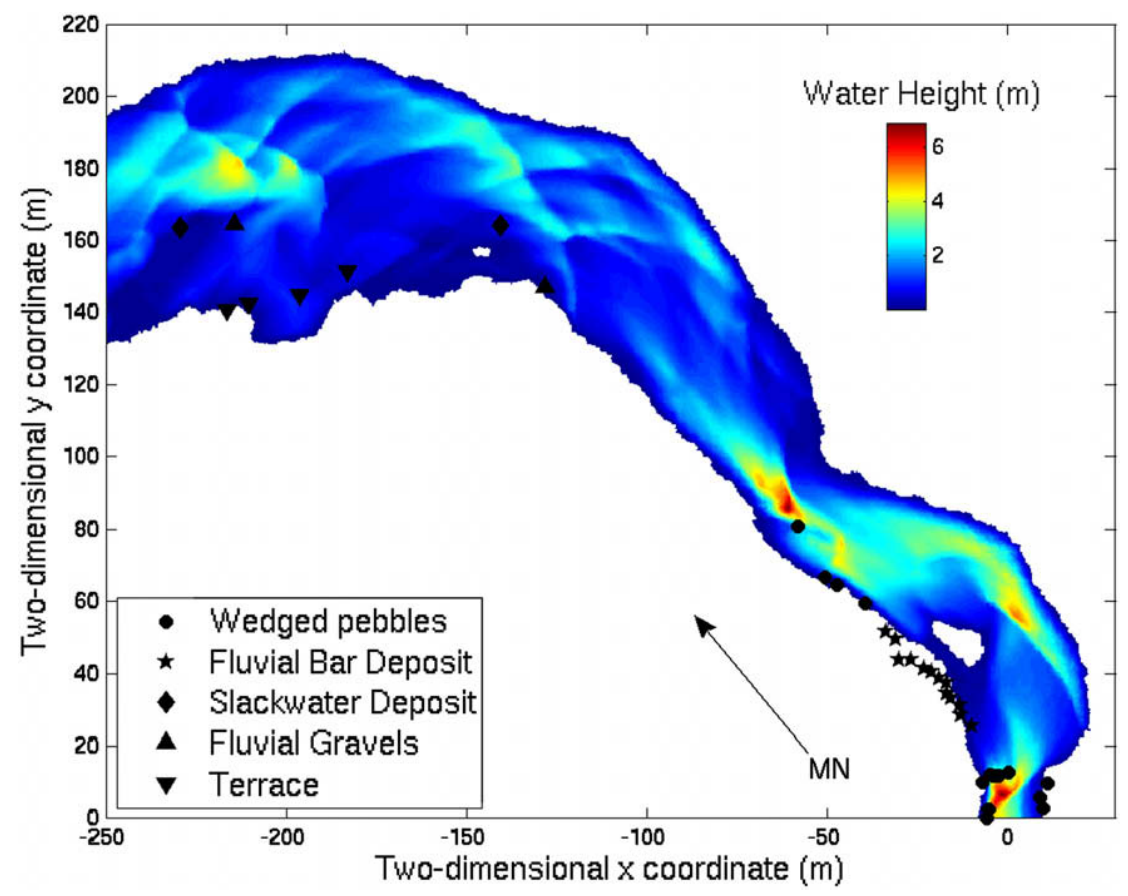

Figure 10 Plan view of the reconstructed water surface shown in Fig. 9.

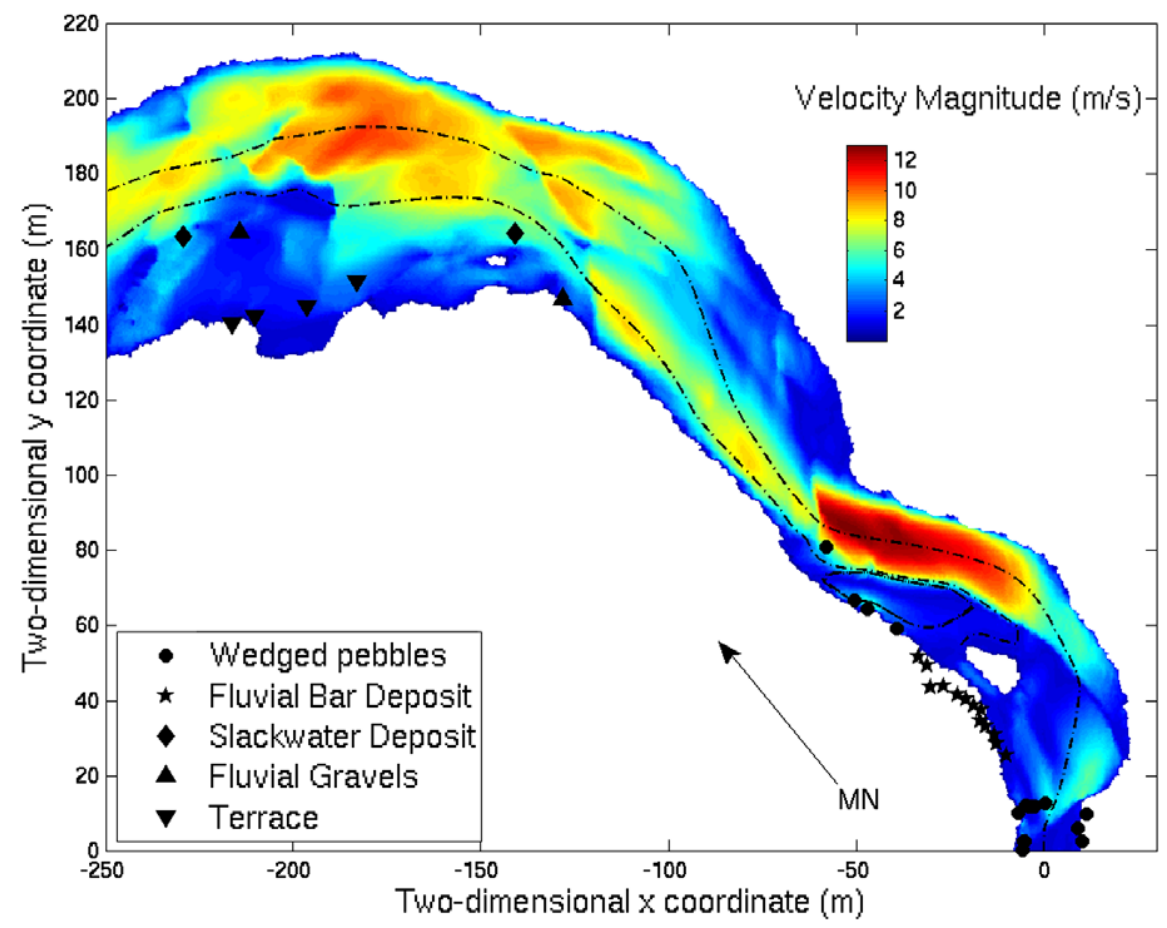

Figure 11 Velocity contour for the case shown in Fig. 9. Also shown are the most representative streamlines (dashed-dotted line). 
gion $90<y<120 \mathrm{~m}$, and also from the water height isocurves, slowing down, expanding and shallowing as the flood advances along the reach up to the first fluvial gravel evidence. In this region the flow exhibits a quasi one-dimensional state, matching the one-dimensional and averaged two-dimensional results with success, although the water surface is not flat (remember the cross-section $G$ in Figs. $8 a$ and 9). Leaving and reaching the first fluvial gravel and slack water deposit, respectively, the bed topography again imposes a change on the flood direction, such that maximum flow velocities are found at the outer bank, and the PSIs (terrace, slack water deposit and fluvial gravel) are again submerged by the simulated flood.

The steady hypothesis involved in the results discussed above can now be evaluated by comparing the characteristic time to fill the analysed reach with respect to the char-
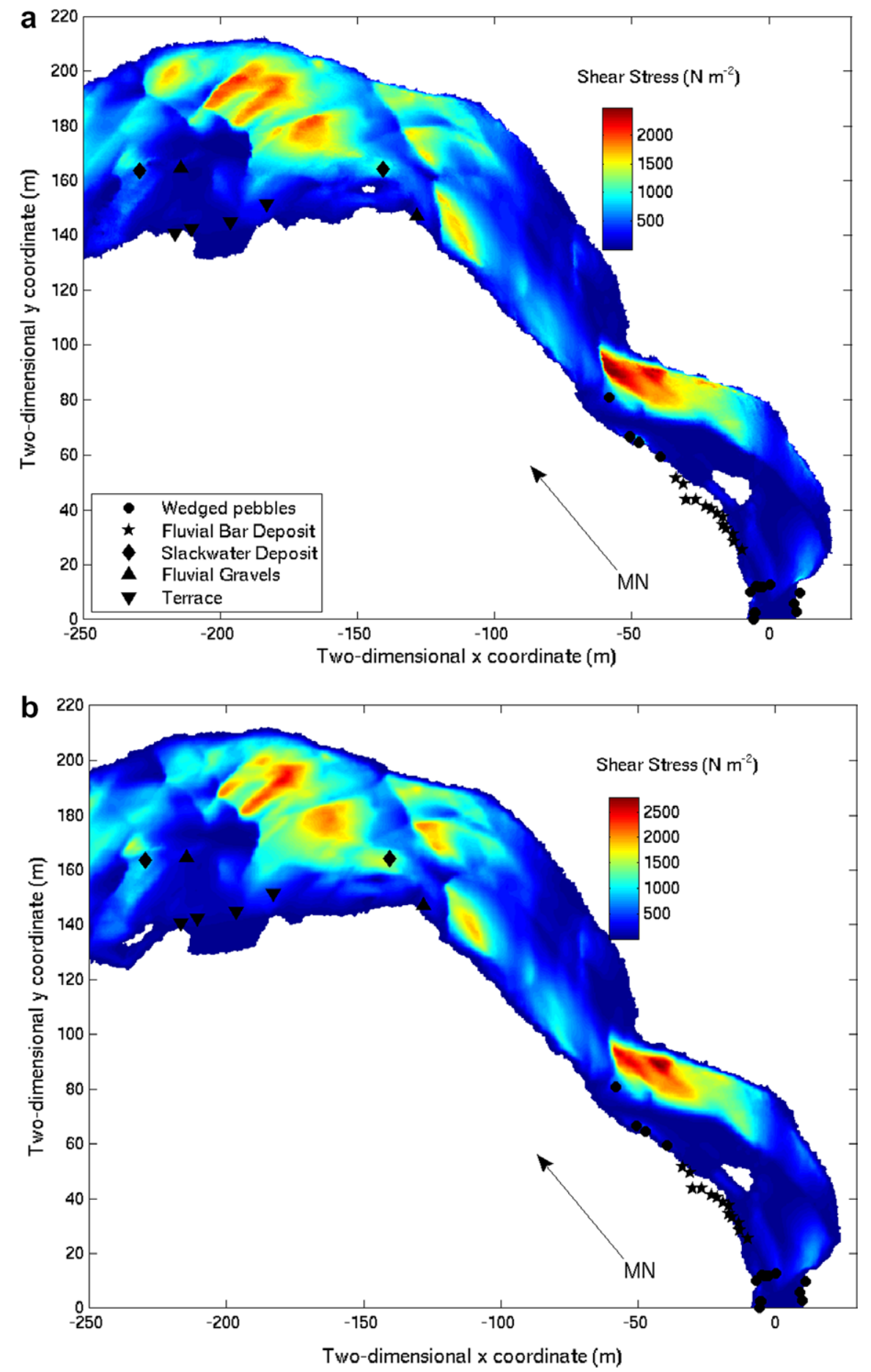

Figure 12 Shear stress contour for (a) the case shown in Fig. 9, (b) the case shown in Fig. 9 but increasing the bed roughness up to $k_{\mathrm{s}}=1.4 \mathrm{~m}$. The case (c) and (d) is similar to (a) and (b), respectively, but with the flow discharge $Q=550 \mathrm{~m}^{3} \mathrm{~s}^{-1}$. 

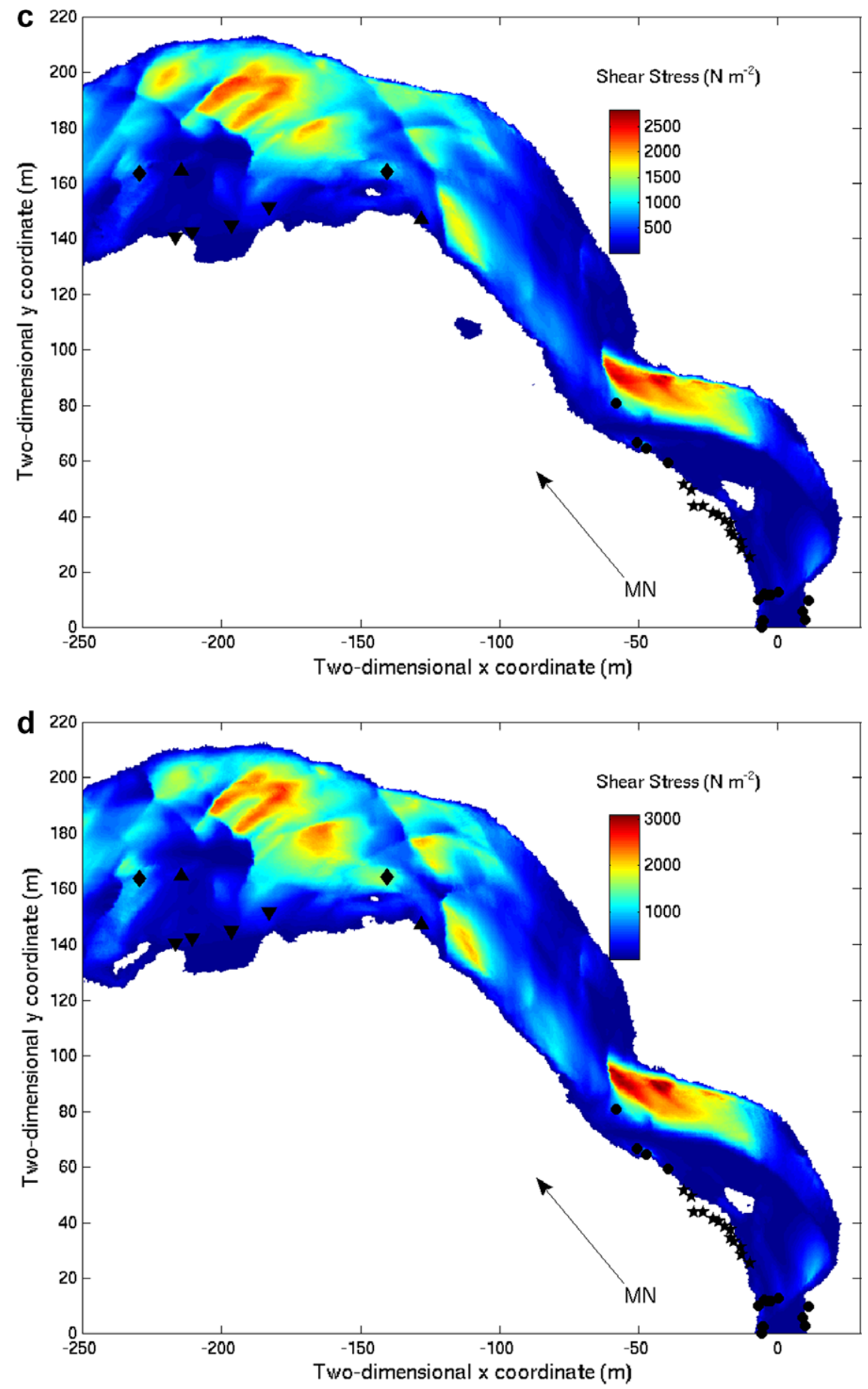

Figure 12 (continued)

acteristic time of the flood event. The order of magnitude of the time required to fill the reach under consideration $t_{\text {opt }}$ can be estimated as the ratio between the wetted volume $V_{\text {opt }}$ and the flow discharge $Q_{\text {opt }}$ :

$t_{\mathrm{opt}} \equiv \frac{V_{\mathrm{opt}}}{Q_{\mathrm{opt}}}$.

In the same way, the steady duration of the outburst flood $t_{\text {flood }}$ is computed from the released volume of water $V \approx 1.6 \times 10^{6} \mathrm{~m}^{3}$ (Hagen, 1944) and the flow rate $Q_{\mathrm{opt}}$ :

$$
t_{\text {flood }} \equiv \frac{V}{Q_{\text {opt }}}
$$

The ratio between Eqs. (17) and (18) leads to the relation $t_{\text {opt }} / t_{\text {flood }}=V_{\text {opt }} / V$, where the volume $V_{\text {opt }}$ is a function of the flow rate $Q_{\text {opt }}$, inflow water height $h_{i}$ and bed roughness $k_{s}$. Thus, when the released volume $V$ is much larger than the wetted volume of the simulated reach $V_{\text {opt }}$, the characteristic time to fill the reach $t_{\mathrm{opt}}$ is much lower than the flood event duration $t_{\text {flood }}$. Taking into account that the order of 
magnitude of the wetted volume is $\mathrm{O}\left(10^{4}\right)$ (in the particular case of the retrodicted discharge $Q_{\text {opt }} \approx 450 \mathrm{~m}^{3} \mathrm{~s}^{-1}$ the exact value is $V_{\text {opt }} \approx 2 \times 10^{4} \mathrm{~m}^{3}$ ), one obtains $t_{\text {opt }} \approx 0.01 t_{\text {flood }}$ which confirms that the steady hypothesis is appropriate in this work.

\section{Bed shear stress distributions}

Uncertainties in specifying roughness values accurately, as well as boundary condition values and the criteria adopted to compute RMS errors, may also have implications for applications concerned with hydraulic analysis of largemagnitude events. Such applications are important in assessing sediment transport, erosion and sedimentation, and the risks of damage to structures posed by events of this type. To illustrate this, Fig. 12 shows bed shear stress values simulated for several scenarios of the reconstructed 1943 outburst event: the shear stress values plotted in (a) correspond with the case previously described $\left(Q=450 \mathrm{~m}^{3} \mathrm{~s}^{-1}\right.$, $h_{\mathrm{i}}=4.45$ and $k_{\mathrm{s}}=0.8 \mathrm{~m}$ ); case (b) differs from due to the roughness value (now $k_{\mathrm{s}}=1.4 \mathrm{~m}$ ); to analyse the influence of the discharge simulated, the two last plots (c) and (d) are equivalent to (a) and (b), respectively, but with an increased discharge of $Q=550 \mathrm{~m}^{3} \mathrm{~s}^{-1}$. The magnitude of the bed shear stress,

$\left|\tau_{\mathrm{b}}\right|=\frac{f}{8} \rho\left(u^{2}+v^{2}\right)$,

was computed according to the definition of the two-dimensional friction term [see Eq. (7)]. The critical shear stress value, estimated for the $D_{84}$ bed-material particle size by averaging all the estimates listed in Table 6 , is $\tau_{\mathrm{c}}=577.3 \mathrm{~N} \mathrm{~m}^{-2}$. The results indicate that bed shear stress values exerted by the outburst event exceed the critical shear stress along most of the outer bank of the study reach, independent of the specified value of $k_{\mathrm{s}}$. Very high values of simulated bed shear stress (up to $3000 \mathrm{~N} \mathrm{~m}^{-2}$ for $k_{\mathrm{s}}=1.4 \mathrm{~m}$ and $Q=550 \mathrm{~m}^{3} \mathrm{~s}^{-1}$ ) attest to the significant erosive potential of the flood, which is verified by field observations of very large, fluvially transported, boulders and eroded bedrock throughout the reach (Fig. 2). Only in the inner most portion of the study reach do simulated shear stresses fall below the critical value, consistent with field observations of boulder splays in this location. While the results from each different simulation are, therefore, broadly consistent, there is quantitative difference in the detail. Most obviously, the magnitudes of simulated mean bed shear stress values diverge significantly as $k_{\mathrm{s}}$ and $Q$ are varied. Dif- ferences in simulated bed shear stress values for the $k_{\mathrm{s}}=0.8$ and $1.4 \mathrm{~m}$ simulations are typically in excess of $500 \mathrm{~N} \mathrm{~m}^{-2}$. In the context of estimating sediment transport capacity and the erosive potential of the flood, these differences are very large. As with flow discharge estimation, it would seem that difficulties in specifying bed roughness $k_{\mathrm{s}}$ accurately can lead to considerable uncertainty when estimating the hydraulic characteristics, and hence capacity to perform geomorphic work, of former floods in high-gradient channels.

\section{Summary and conclusion}

The 1943 outburst flood from the Glacier du Mont Miné has been reconstructed using one- and two-dimensional shallow water modelling techniques. Retrodicted flood discharges have been determined by minimizing the RMS error of the water surface height computed following two approaches, comparing the simulated water surface height first with respect to an approximate former water profile and then with respect to individual PSI values. The sensitivity of the retrodicted flood discharge to variations in the model input parameters was also assessed.

It was found that averaged estimates of flow discharge magnitude derived from the two-dimensional modelling varied between 358 and $454 \mathrm{~m}^{3} \mathrm{~s}^{-1}$ as a result of varying the bed roughness $k_{\mathrm{s}}$ and inflow water height $h_{\mathrm{i}}$ in the range $k_{\mathrm{s}}=0.8-1.4 \mathrm{~m}$ and $h_{\mathrm{i}}=3.31-6 \mathrm{~m}$. In contrast, the onedimensional reconstruction of the outburst flood suggests that the flow discharge magnitude is within the range 429-557 $\mathrm{m}^{3} \mathrm{~s}^{-1}$. Discrepancies between the one-dimensional and cross-sectional averaged two-dimensional results are due to a recirculation zone that is reproduced by the twodimensional model, but not by the one-dimensional one. In the vicinity of the recirculation zone, large differences appeared in the one-dimensional water depth but not far away, the one-dimensional Saint-Venant equations reproduce with accuracy the averaged two-dimensional solution even in the presence of channel bends. Thus, one-dimensional reconstruction of glacier outburst floods can be regarded as a useful method for estimating flood discharges in the absence of dead zones. Moreover, one- and two-dimensional coupled models (Gejadze and Monnier, 2007), which enrich the one-dimensional shallow water physics with local twodimensional effects, may be of special interest for glacier outburst reconstructions, allowing model parameter exploration with minimal computational cost.

Table 6 Comparison of critical shear stress values estimated using a range of flow competence equations

\begin{tabular}{llll}
\hline Author(s) & Formula $^{\mathrm{a}}$ & $\begin{array}{l}\text { Critical shear stress for } \mathrm{D}_{50} \\
\text { particle size }\left(\mathrm{N} \mathrm{m}^{-2}\right)\end{array}$ & $\begin{array}{l}\text { Critical shear stress for } D_{84} \\
\text { particle size }\left(\mathrm{N} \mathrm{m}^{-2}\right)\end{array}$ \\
\hline $\begin{array}{l}\text { Baker and Ritter } \\
\text { (1975) }\end{array}$ & $\tau_{\mathrm{c}}=0.30 D^{1.49}$ & 373.2 & 623.1 \\
Costa (1983) & $\tau_{\mathrm{c}}=0.163 D^{1.213}$ & 351.3 & 533.3 \\
Komar (1989) & $\tau_{\mathrm{c}}=728.4 D$ & 407.9 & 575.4 \\
Mean value & - & 377.5 & 577.3 \\
\hline
\end{tabular}

${ }^{a}$ All the formulas listed here require the particle size $(D)$ to be specified in millimeters. 
The results of the sensitivity analyses suggest that the flow discharge values are estimated to within a precision of $\pm 43 \%$ in the one-dimensional model, whereas a smaller sensitivity of $\pm 24 \%$ is obtained when using the two-dimensional simulations. Hence, our results imply that the level of precision of flow discharge values reconstructed using shallow water modelling may be moderately well constrained in very steep valleys similar to the one investigated here, so long as a physical realistic (i.e. two-dimensional) modelling approach is employed.

\section{Acknowledgements}

This study was funded by the Royal Geographical Society (HSBC Holdings Small Grant) and by the Ministerio de Educación y Ciencia of Spain (PB under Grant No. AP-2004-3719). Staff from the Cartographic Unit of the University of Southampton drafted the illustrations. Particular thanks are due to Jon Barnes, Doug Booker, Jaye Cockayne, Natasha Darby, Nick Odoni, Kat Townsend, and Nick Wallerstein for their invaluable assistance in the field.

\section{Appendix A. Validity of the one-dimensional shallow water model}

In this paper, a one-dimensional shallow water model was employed. This assumption is likely to be valid under specific conditions. Defining the set of non-dimensional variables that follow:

$\hat{x} \equiv \frac{x}{L}, \quad \hat{y} \equiv \frac{y}{B}, \quad \hat{z}_{\mathrm{s}} \equiv \frac{z_{\mathrm{s}}}{\Delta z_{\mathrm{s}}}, \quad \hat{u} \equiv \frac{u}{U}, \quad \hat{v} \equiv \frac{v}{V}, \quad \hat{h} \equiv \frac{h}{H}$,

in which $L$ and $B$ are the characteristic length scale in the longitudinal $x$ and transversal direction $y$, respectively, $U$ is the velocity along the streamwise direction, $V$ is the velocity in the crosswise direction, $\Delta z_{s}$ represents a characteristic variation in the water surface elevation $z_{\mathrm{s}} \equiv h+S$, and $H$ is a characteristic water depth, the two-dimensional shallow water continuity equations (1)-(4) are rewritten as

$\frac{\partial \hat{h} \hat{u}}{\partial \hat{x}}+\frac{V L}{U B} \frac{\partial \hat{h} \hat{v}}{\partial \hat{y}}=0$.

The continuity equation (A.2) establishes the following relation between the two components of the velocity vector:

$1 \sim \frac{V L}{U B} \Rightarrow V \sim \frac{B}{L} U$.

Therefore, the flow is quasi unidirectional when the longitudinal length scale $L$ is much larger than the characteristic width $B$ :

$V \ll U$ with $\frac{B}{L} \ll 1$.

Moreover, under these conditions the flat surface hypothesis intrinsic to the one-dimensional model can be justified. Taking into account (A.3) and (A.4), the momentum balance equations (1)-(7) read:

$$
\begin{aligned}
& \frac{\partial \hat{h} \hat{u}^{2}}{\partial \hat{x}}+\frac{g \Delta z_{s}}{U^{2}} \hat{h} \frac{\partial \hat{z}_{s}}{\partial \hat{x}}+\frac{\partial \hat{h} \hat{u} \hat{v}}{\partial \hat{y}}+\frac{f}{8} \frac{L}{H}|\hat{u}| \hat{u}=0, \\
& \frac{\partial \hat{h} \hat{v}^{2}}{\partial \hat{y}}+\frac{g \Delta z_{s}}{U^{2}}\left(\frac{L}{B}\right)^{2} \hat{h} \frac{\partial \hat{z}_{s}}{\partial \hat{y}}+\frac{\partial \hat{h} \hat{u} \hat{v}}{\partial \hat{x}}+\frac{f}{8} \frac{L}{H}|\hat{u}| \hat{v}=0 .
\end{aligned}
$$

For a general flow regime in which all the terms in Eq. (A.5) are equally important, it yields:

$\frac{g \Delta z_{\mathrm{s}}}{U^{2}} \sim \frac{f}{8} \frac{L}{H} \sim 1$

and thus the momentum balance along the transversal direction y (Eq. (A.6)) reduces to:

$\hat{h} \frac{\partial \hat{z}_{s}}{\partial \hat{y}}=0$

with errors of order $O\left(B^{2} / L^{2}\right)$. Then, the integration of the equation shown above implies $\hat{\mathbf{Z}}_{\mathrm{s}} \neq \hat{\mathbf{Z}}_{\mathrm{s}}(\hat{\mathbf{y}})$ with $\hat{h}>0$.

Finally, to recover the Saint-Venant equations (8)-(14) both the continuity equation (A.2) and the $x$-momentum balance (A.5) have to be integrated through the cross-section. In this step, the net contribution of the terms involving partial derivatives with respect to the transversal coordinate $y$ is zero since the water height vanishes on the banks, and hence the transversal velocity $\hat{v}$ is not considered in the one-dimensional approach. The resulting equations (8)-(14) are strictly valid only for straight channels, neglecting the contribution of the velocities perpendicular to the onedimensional axis in the global momentum balance. When the channel curves (with a characteristic radius $R$ ), these equations are locally valid with an additional error of order $\mathrm{O}\left(R_{\mathrm{h}} / R\right)$ due to the Cartesian coordinates employed in the computation of the cross-sectional area $A$ and flow rate $Q$, and therefore can be carefully used when the hydraulic radius $R_{\mathrm{h}}$ is much smaller than the characteristic curvature of the bend $R$.

\section{References}

Acreman, M.C., 1989. Extreme historical UK floods and maximum flood estimation. Journal of the Institution of Water Engineers and Managers 3, 404-412.

Alho, P., Aaltonen, J., 2008. Comparing a 1D hydraulic model with a 2D hydraulic model for the simulation of extreme glacial outburst floods. Hydrological Processes 22, 1537-1547.

Arnell, N.W., 1992. Factors controlling the effects of climatic change on river flow regimes in a humid temperate environment. Journal of Hydrology 132, 321-342.

Baker, V.R., 1973. Paleohydrology and sedimentology of Lake Missoula flooding in eastern Washington. Geological Society of America Special Paper, 144.

Baker, V.R., 1977. Stream channel response to floods, with examples from central Texas. Geological Society of America Bulletin 88, 1057-1071.

Baker, V.R., 1987. Paleoflood hydrology and extraordinary flood events. Journal of Hydrology 96, 79-99.

Baker, V.R., Benito, G., Rudoy, A.N., 1993. Paleohydrology of late Pleistocene superflooding, Altay Mountains, Siberia. Science 259, 348-350.

Baker, V.R., Kale, V.S., 1998. The role of extreme floods in shaping bedrock channels. In: Tinkler, K., Wohl, E. (Eds.), Rivers Over Rock: Fluvial Processes in Bedrock Channels. American Geophysical Union, Washington, DC, pp. 153-165. 
Baker, V.R., Ritter, D.B., 1975. Competence of rivers to transport coarse bedload material. Geological Society of America Bulletin 86, 975-978.

Batchelor, G.K., 1967. An Introduction to Fluid Dynamics. Cambridge University Press, Cambridge, UK.

Beecroft, I., 1981. Sediment transport during a glacial outburst from the Tsidiore Nouve Glacier. Journal of Geological Society $140,321$.

Benito, G., 1997. Energy expenditure and geomorphic work of the cataclysmic Missoula flooding in the Columbia River Gorge, USA. Earth Surface Processes and Landforms 22, 457-472.

Blayo, E., Debreu, L., 2005. Revisiting open boundary conditions from the point of view of characteristic variables. Ocean Modelling 9 (3), 231-252.

Bretz, J.H., 1923. The channeled Scabland of the Columbia Plateau. Journal of Geology 31, 617-649.

Bohorquez, P., Fernandez-Feria, R., 2008. Transport of suspended sediment under the dam-break flow on an inclined plane bed of arbitrary slope. Hydrological Processes 22, 2615-2633.

Brackbill, J.U., Kothe, D.B., Zemach, C., 1992. A continuum method for modeling surface tension. Journal of Computational Physics 100 (2), 335-354.

Brown, A.G., 1996. Palaeohydrology: prospects and future advances. In: Branson, J., Brown, A.G., Gregory, K.J. (Eds.), Global Continental Changes: The Context of Palaeohydrology, vol. 115. Geological Society Special Publication, pp. 257-265.

Carling, P.A., 1996. A preliminary palaeohydraulic model applied to late Quaternary gravel dunes: Altai Mountains, Siberia. In: Branson, J., Brown, A.G., Gregory, K.J. (Eds.), Global Continental Changes: The Context of Palaeohydrology, vol. 115. Geological Society Special Publication, pp. 165-179.

Carling, P.A., Grodek, T., 1994. Indirect estimation of ungauged peak discharges in a bedrock channel with reference to design discharge selection. Hydrological Processes 8, 497-511.

Carrivick, J., 2006. Application of 2D modelling of high-magnitude outburst floods: an example from Kverkfjöll, Iceland. Journal of Hydrology 321, 187-199.

Carrivick, J., 2007. Hydrodynamics and geomorphic work of jökulhlaups (glacial outburst floods) from Kverkfjöll volcano, Iceland. Hydrological Processes 21, 725-740.

Clague, J.J., Evans, S.G., 1997. The 1994 jökulhlaup at Farrow Creek, British Columbia, Canada. Geomorphology 19, 77-87.

Colebrook, C.F., 1939. Turbulent flow in pipes with particular reference to the transition region between the smooth- and rough-pipe laws. Journal of the Institute of Civil Engineers, 133156.

Commune d'Evolène, 1998. Concept de protection contre les crues. Tech. Rep., REBORD SA Consulting Engineers, Vtroz, Switzerland.

Cook, J.M., 1987. Quantifying peak discharges for historical floods. Journal of Hydrology 96, 29-40.

Costa, J.E., 1983. Paleohydraulic reconstruction of flash-flood peaks from boulder deposits in the Colorado Front Range. Geological Society of America Bulletin 94, 986-1004.

Cunge, J.A., Holly, F.M., Verwey, A., 1980. Practical Aspects of Computational River Hydraulics. Pitman, London, UK.

Davidian, J., 1984. Computation of water surface profiles in open channels. TWRI Book 3: Application of Hydraulics. USGS (Ch. A15).

Denlinger, R.P., O'Connell, D.R.H., 2003. Two-dimensional flow constraints on catastrophic outflow of glacial Lake Missoula over three-dimensional terrain. In: Ely, L.L., O'Connor, J.E., House, P.K. (Eds.), Abstracts and Program from Third International Paleoflood Conference, Hood River, Orgeon, pp. 1-7.

D'Errico, J., 2006. Surface fitting using Gridfit. MATLAB Central File Exchange.

Desloges, J.R., Church, M., 1992. Geomorphic implications of glacier outburst flooding: Noeick River valley, British Columbia. Canadian Journal of Earth Sciences 29, 551-564.
Enzel, Y., Ely, L.L., House, P.K., 1996. Magnitude and frequency of Holocene palaeofloods in the southwestern United States: a review and discussion of implications. In: Branson, J., Brown, A.G., Gregory, K.J. (Eds.), Global Continental Changes: The Context of Palaeohydrology, vol. 115. Geological Society Special Publication, pp. 121-137.

Eskilsson, C., Árnason, J.I., D, R., 2002. Simulation of the jökulhlaup on Skeiadarársandur, southeast Iceland, in November 1996 using MIKE 21. In: Snorrason, A., Finnsdottir, H.P., Moss, M.E. (Eds.), The Extremes of the Extremes: Extraordinary Floods. No. 271. The International Association of Hydrological Science Publication, pp. 37-43.

Evans, S.G., Clague, J.J., 1994. Recent climatic change and catastrophic geomorphic processes in mountain environments. Geomorphology 10, 107-128.

Gejadze, I.Y., Monnier, J., 2007. On a 2D 'zoom' for the 1D shallow water model: coupling and data assimilation. Computer Methods in Applied Mechanics and Engineering 196, 4628-4643.

Gregory, K.J., 1976. Lichens and the determination of river channel capacity. Earth Surface Processes 1, 273-285.

Gupta, A., 1988. Large floods as geomorphic events in the humid tropics. In: Baker, V.R., Kochel, R.C., Patton, P.C. (Eds.), Flood Geomorphology. Wiley, New York, NY, pp. 301-315.

Haeberli, W., 1983. Frequency and characteristics of glacier floods in the Swiss Alps. Annals of Glaciology 4, 85-90.

Haeberli, W., Alean, J.C., Mller, P., Funk, M., 1989. Assessing risks from glacier hazards in high mountain regions: some experiences in the Swiss Alps. Annals of Glaciology 13, 96-102.

Hagen, T., 1944. Der Gletscherausbruch von Ferpècle. Die Alpen (SAC) XX, 269-274.

Honnorat, M., Marin, J., Monnier, J., 2007a. Dassflow: data assimilation for river flows. <http://dassflow.gforge.inria.fr>.

Honnorat, M., Marin, J., Monnier, J., Lai, X., 2007b. Dassflow v1.0: a variational data assimilation software for $2 \mathrm{D}$ river flows. Research Report 6150, INRIA. <https://hal.inria.fr/docs/00/13/ 79/27/PDF/RR-6150.pdf>.

Hupp, C.R., 1988. Plant ecological aspects of flood geomorphology and paleoflood history. In: Baker, V.R., Kochel, R., Patton, P. (Eds.), Flood Geomorphology. Wiley, New York, NY, pp. 335356.

Hydrologic Engineering Centre, 2001. HEC-RAS River Analysis System. Hydraulic Reference Manual ver. 3.0. Army Corps of Engineering, Davis, CA.

Jarrett, R.D., 1990. Paleohydrologic techniques used to define the spatial occurrence of floods. Geomorphology 3, 181-195.

Kidson, R.L., Richards, K.S., Carling, P.A., 2006. Hydraulic model calibration for extreme floods in bedrock-confined channels: case study from northern Thailand. Hydrological Processes 20, 329-344.

Kochel, R.C., Baker, V.R., 1988. Paleoflood analysis using slackwater deposits. In: Baker, V.R., Kochel, R.C., Patton, P.C. (Eds.), Flood Geomorphology. Wiley, New York, NY, pp. 357-376.

Kochel, R.C., Baker, V.R., Patton, P.C., 1982. Paleohydrology of Southwestern Texas. Water Resources Research 18, 11651183.

Komar, P.D., 1989. Flow-competence evaluations of the hydraulic parameters of floods: an assessment of the technique. In: Beven, K., Carling, P. (Eds.), Floods: Hydrological, Sedimentological and Geomorphological Implications. Wiley, Chichester, pp. 107-134.

LeVeque, R.J., 2002. Finite Volume Methods for Hyperbolic Problems. Cambridge University Press.

Maizels, J., 1997. Jökulhlaup deposits in proglacial areas. Quaternary Science Reviews 16, 793-819.

Miller, A.J., 1998. Valley morphology and boundary conditions influencing spatial patterns of flood flow. In: Costa, J.E., Miller, A.J., Potter, K.W., Wilcock, P.R. (Eds.), Natural and Anthropogenic Influences in Fluvial Geomorphology. American Geophysical Union, Washington, DC, pp. 57-81. 
Miller, A.J., Cluer, B.L., 1998. Modeling considerations for simulation of flow in bedrock channels. In: Tinkler, K., Wohl, E. (Eds.), Rivers Over Rock: Fluvial Processes in Bedrock Channels. American Geophysical Union, Washington, DC, pp. 61-104.

O'Connor, J.E., Baker, V.R., 1992. Magnitudes and implications of peak discharges from Glacial Lake Missoula. Geological Society of America Bulletin 104, 267-271.

O'Connor, J.E., Ely, L.L., Wohl, E.E., Stevens, L.E., Melis, T.S., Kale, V.S., Baker, V.R., 1994. A 4500-year record of large floods on the Colorado River in the Grand Canyon. The Journal of Geology 102, 1-9.

Osher, S., Sethian, J.A., 1988. Fronts propagating with curvaturedependent speed: algorithms based on Hamilton-Jacobi formulations. Journal of Computational Physics 79, 12-49.

Pappenberger, F., Beven, K., Horrit, M., Blazkova, S., 2005. Uncertainty in the calibration of effective roughness parameters in HEC-RAS using inundation and downstream level observations. Journal of Hydrology 302, 46-69.

Pruess, J., Wohl, E.E., Jarrett, R.D., 1998. Methodology and implications of maximum paleodischarge estimates for mountain channels, Upper Animas River Basin, Colorado, USA. Arctic and Alpine Research 30, 40-50.

Serghides, T.K., 1984. Estimate friction factor accurately. Chemical Engineering 91, 63-64.

Sethian, J.A., Smereka, P., 2003. Level set method for fluid interfaces. Annual Review of Fluid Mechanics 35, 314-372.

Shroba, R.R., Schmidt, P.W., Crosby, E.J., Hansen, W.R., Soule, J.M., 1979. Storm and flood of July 31-August 1, 1976, in the Big Thompson River and Cache la Poudre River basins, Larimer and Weld Counties, Colorado Part B. Geologic and geomorphic effects in the Big Thompson Canyon area, Larimer
County. U.S. Geological Survey Professional Paper 1115, 87152.

Streeter, V.L., 1951. Fluid Mechanics. McGraw-Hill, New York.

Tweed, F.S., Russell, A.J., 1999. Controls on the formation and sudden drainage of glacier-impounded lakes: implications for jökulhlaup characteristics. Progress in Physical Geography 23, 79-110.

Vázquez-Cendón, M., 1999. Improved treatment of source terms in upwind schemes for the shallow water equations in channels with irregular geometry. Journal of Computational Physics 148, 497-526.

Walder, J.S., Driedger, C.L., 1994. Rapid geomorphic change caused by glacial outburst floods and debris flows along Tahoma Creek, Mount Rainier, Washington, USA. Arctic and Alpine Research 26, 319-327.

Williams, G.P., 1983. Paleohydrological methods and some examples from Swedish fluvial environments I: cobble and boulder deposits. Geografiska Annaler 65A, 227-243.

Williams, G.P., 1984. Paleohydrologic equations for rivers. In: Costa, J.E., Fleisher, P.J. (Eds.), Developments and Applications of Geomorphology. Springer-Verlag, Berlin, pp. 343-367.

Wohl, E.E., 1995. Estimating flood magnitude in ungauged mountain channels, Nepal. Mountain Research and Development 15, 6976.

Wohl, E.E., 1998. Uncertainty in flood estimates associated with roughness coefficient. Journal of Hydraulic Engineering 124 (2), 219-223.

Wright, N.G., 2005. Introduction to numerical methods for fluid flow. In: Bates, P., Lane, S., Ferguson, R. (Eds.), Computational Fluid Dynamics: Applications in Environmental Hydraulics. Wiley, pp. 147-168. 